\title{
The effect of changes in the statutory minimum working age on educational, labor and health outcomes ${ }^{\aleph}$
}

\author{
SERGI JIMENEZ-MARTIN \\ UNIVERSITAT POMPEU FABRA, BARCELONA GSE AND FEDEA \\ JUDIT VALL CASTELLO \\ CENTRE FOR RESEARCH IN ECONOMICS AND HEALTH \\ UNIVERSITAT POMPEU FABRA \\ ELENA DEL REY \\ UNIVERSITAT DE GIRONA
}

\begin{abstract}
In this paper we explore the effects of a labor market reform that changed the statutory minimum working age in Spain in 1980. In particular, the reform raised the statutory minimum working age from 14 to 16 years old, while the minimum age for attaining compulsory education was kept at 14 until 1990. To study the effects of this change, we exploit the different incentives faced by individuals born at various times of the year before and after the reform. We show that, for individuals born at the beginning of the year, the probabilities of finishing both the compulsory and the post-compulsory education level increased after the reform. In addition, we find that the reform decreases mortality while young (16-25) for both genders while it increases mortality for middle age women (26-40). We provide evidence to proof that the latter increase is partly explained by the deterioration of the health habits of affected women. Together, these results help explain the closing age gap in life expectancy between women and men in Spain.
\end{abstract}

\footnotetext{
" We acknowledge financial help from project ECO2014-52238-R as well as from a RECERCAIXA grant. We would like to thank participants to the seminars at Murcia, UPF, URV, IEB (UB), UPO, The Centre for Health Service Economics \& Organization at Oxford University, $39^{\text {th }}$ Congress of the Spanish Economic Association, the Congress of the Spanish Health Economic Association in Granada and the Barcelona GSE Winter Workshop (2015).
} 


\section{Introduction}

There are now several papers in the literature that establish the positive association between the number of years of education and health outcomes. Still, the causal relationship between these two factors has proved more difficult to determine. Most of the papers in the literature have used changes in the laws that set the minimum school leaving age to assess the causal impact of more education on health. ${ }^{1}$ These papers tend to report positive effects of education on health outcomes and health behaviors (Oreopoulos, 2006; Clark and Royer, 2013; Heckman et al, 2014, Brunello et al. 2015; among others) although the size of this impact seems a more contested question. In contrast, if we focus on more extreme health conditions such as mortality, the agreement in the literature is far from clear. While Lleras-Muney (2005) for the USA finds significant positive effects of education on mortality, Clark and Royer (2013) for the UK find no significant effects. ${ }^{2}$ These two papers use a similar econometric model (regression discontinuity).

Although the evidence in the literature is scarce and mixed, it is important to determine the causal effect of education on health, and even on more extreme events such as mortality. This importance is clearly more apparent in the case of developing countries, where educational levels are still very low and mortality rates are high. However, it is also relevant for developed economies such as the USA or the UK that have set high school completion goals and are considering further increases in compulsory school leaving ages in an attempt to improve future health outcomes of affected individuals. ${ }^{3}$

In this paper, we contribute to this literature by focusing on an increase in the minimum statutory working age from age 14 to 16 that was introduced in Spain in $1980 .{ }^{4}$ The case of the Spanish reform in 1980, just a few years after the end of Franco's dictatorial regime in 1975, constitutes an excellent example for developing countries as some of them have the same age threshold than in Spain before the 1980 reform. $^{5}$ By that time, Spain was still a developing country and a large majority of the population barely had a primary level of education (the proportion of the population with at most lower secondary education in 1980 was about 60 per cent for both genders, see Felgueroso et al, 2014). So, as in many non-develop and developing countries, there was a lot of room for improvement.

From a political and social point of view the early 1980's was a very turbulent period in Spain, because of the approval of the new constitution. Many other changes were also introduced in the legislation after

\footnotetext{
${ }^{1}$ These changes in compulsory education have also been used to estimate the causal effect of education on other outcomes such as wages (see Dickson and Harmon, 2011 for a review), marital status (Anderberg and Zhu, 2014), fertility (Haveman and Wolfe, 1984), criminal behaviour (o, 2004) and voter turnout (Milligan, Moretti \& Oreopoulos, 2004 and Dee, 2004).

${ }^{2}$ Oreopoulos (2006) and Clark and Royer (2013) analyze the same schooling reform in 1947 in the UK but the paper by Clark and Royer focuses not only on the reform in 1947 but also on an additional reform introduced in 1972 also in the UK.

${ }^{3}$ See the Healthy People 2010 plan for the USA which sets a high school completion goal of $90 \%$ or British government plans to increase compulsory schooling age to 18 (Seager, 2009).

${ }^{4}$ Edmonds and Shresta (2012) have analyzed the effects of different compulsory schooling laws and statutory minimum working age on education and child labor in 59, mostly low income, countries.

${ }^{5}$ Before the reform in 1980, the minimum age to work in Spain was set at the same age (14 years old) than compulsory education. Currently, in some developing countries such as Bolivia and the Dominican Republic the minimum age for employment is 14, which is the same than the age of compulsory education.
} 
Franco's death, especially around 1980, which is precisely the years when the cohorts affected by the 1980 reform were becoming adults. Gender discrimination in terms of access to upper education and work was disappearing very rapidly (see Figure 1). ${ }^{6}$ It is particularly important to stress that, during that period, risky behaviours were at their very highs. In particular, substance abuse as well as car accidents were at or about to reach their historical maximum. ${ }^{7}$

Figures A1, A2 and A3 in the appendix summarize the different incentives to work and study for 14 years old kids at the various points in time in Spain. Before the reform, both the age of compulsory education and the minimum age to work were set at 14. Under these circumstances, individuals born at the beginning of the year found themselves legally able to work before attaining compulsory education. This provided an incentive (or at least the possibility) of leaving school early. Individuals born at the end of the year attained the legal working age having completed compulsory education, so that, except in case of grade repetition, the incentives for them to leave school early were smaller or inexistent. In 1980 when the legal age to work increased to 16, this difference in incentives between those born at the beginning and the end of the year was eliminated. Therefore, we exploit these differences in the incentives to continue studying between individuals born at the beginning and end of the year before and after the reform. As no other labor market or educational reform was implemented until 1990, we are confident that no other confounder is affecting our estimates ${ }^{8}$.

In this institutional context we analyze the effects of the reform first on education attainment and then on mortality. However, we go a step further from proving the causal link of education on mortality, which is the usual thing in the current literature, as we are able to explain two (labor market and health behaviors) of the (many) potential routes that explain this link.

Since the level of social development and labor force participation of men and women at that time was very different, we explore the possibility that the labor, health and mortality implications of the reform were different for them. During the sixties and the seventies education and, especially labor market outcomes were much worse for women (at the time, women were not allowed to work without their spouse's permit). In fact, women were just starting to access to the labor market (the female labor force participation rate in 1980 was about 27 percent). In this context, we expect that access to education would improve the labor market and health outcomes of affected males, which were already showing high participation rates. The case of women seems more complicated to predict as the improve in education would lead to higher access to the labor market which could, in turn, either improve or deteriorate health outcomes of affected women.

\footnotetext{
${ }^{6}$ See Boldrin, Peracchi and Jiménez-Martín, 2001, for a detailed analysis of the Spanish labor market during the 1980's.

7 The literature has shown that aids (Garcia et al. 1999; Instituto de Salud Carlos III 2007; Gomez-Redondo et al. 2005), drug and alcohol abuse (Ribes et al. 2004 and fatal traffic injuries (Saiz-Sanchez et al. 1999; Gine 1992; Puig et al. 2002; Gomez-Redondo et al. 2005; Serra et al. 2006; Puig et al. 2005)) were all peaking during the late seventies and also the eighties, especially for young male cohorts.

${ }^{8}$ In 1990 an educational reform increased the age of compulsory education from 14 to 16 . See Felgueroso et al. (2014) for an evaluation of this reform in Spain.
} 
Access to the labor market for women could favor a process of social masculinization of young women which would translate into worse health habits and, at the end of the day, higher mortality rates. Figure 1 shows first the distance in terms of labor force participation and employment for men and women in cohorts born around 1950 (and earlier) and, second, the process of convergence of labour force participation and employment. Note that this process of social masculinization may help explain the recent convergence trends in life expectations among men and women observed in Spain (see Figure 2) and many other countries.

From a methodological point of view, we follow a differences in differences strategy in order to identify the within cohort effect of the reform. In particular, we identify the effect of the reform by comparing the outcomes of similar individuals, affected and unaffected by the change in incentives to finish compulsory education in each cohort before and after the reform. In our setup, treated (those born between January and May), and control (those born between August and December) individuals only differ in their month of birth. Consequently we can improve the identification strategy with respect to the regular before-after analysis (which would identify the between cohorts effects of the reform), since any other social or political event that could have affected the post-reform cohorts would affect in a similar way our treatment and control groups. Another salient feature of our analysis is the fact that we use both survey and register data from various sources and, when available, we replicate the same analysis using these two alternatively sources.

Our results show that the increase in the age of compulsory education decreased the number of early school leavers (not finishing primary education) in 8594 men and 4053 women for individuals born at the begin of the year in the first ten post reform cohorts. At the same time, the reform also decreased the number of individuals born in the first months of the year not finishing secondary education (dropout) in 25782 men and 13512 women in the first ten post reform cohorts. Therefore, the reform closed the previous gap in early school leavers and dropouts for individuals born at the beginning/end of the year. We also report significant increases in university education for men. Furthermore, the reform reduced the mortality rate of young workers between the two groups of individuals. However, it increased the mortality rate of middle-age treated women. We estimate that the reform saved 1289 treated men and 540 treated women aged 15-25 in the first ten post reform cohorts but it increased mortality in 794 treated women between the ages of 26 and 40. We next explore the channels that can explain this differential effect of the reform for men and women. In terms of labor market outcomes, we report an impact of the reform in increasing the probability of working for both men and women, although the effect is stronger for women. Also, the reform delayed the date of the first labor market experience. However, for men, the labor market impact affected the composition of employment by increasing the skill level of workers and improving the employment conditions of affected men, with fewer temporary contracts. In contrast, for women, the labor market impact comes from a transition from inactivity to employment, without a significant effect on the skill level of affected women. Furthermore, although we estimate a positive impact of the reform on future earnings the 
coefficient is not significant. Thus, our results point to an improvement of the skill level (less construction work and higher skilled jobs) as well as the stability of employment (less temporary contracts) for affected men as well as an increase in employability of affected women.

When we explore the mechanisms, we find that one channel that lead the increase in education to reduce mortality for young individuals born at the beginning of the year is through a reduction in the incidence of working accidents as a result of the improvement in labor market outcomes. Another channel is the reduction in disability and in the consumption of injectable drugs for young men who attain higher levels of education $^{9,10}$. In order to explain the increase in middle-aged women mortality rates, we show that the reform deteriorated the health habits and the incidence of habit-related diseases of these women. Together, these results help explain the closing age gap in life expectancy between women and men in Spain. In Figure 2 we can see that the life expectancy gap at age 60 has remained relatively constant at 4.5 years from 1991 until 2013 whereas the life expectancy gap at birth has decreased from more than 7 years in 1991 to 5.5 years in 2013.

The rest of the paper is organized as follows. Section 2 explains the reform. Section 3 presents a theoretical model that explains how impatience can affect educational decisions of individuals born at different times of the year, and derives some predictions. Section 4 discusses the data and empirical strategy. Section 5 presents the results, and Section 6 concludes.

\section{The reform in 1980; Increase in the minimum age to work from 14 to 16 years old}

The 1970 General Education Law established 8 years of compulsory education, starting on the natural year children turned 6 years old. At the time, the legal age to work was set at 14 years of age. Therefore, during the 70s, individuals turning 14 at the beginning of the year could quit school and start working before having completed compulsory education, thus becoming early school leavers (see Figure A1 in the appendix).

In March 1980 a new law regulating labour relations (Estatuto de los Trabajadores) was approved by the Spanish parliament. It prohibited work for children under the age of 16 . This completely changed things for children born at the beginning of the year when they turned 14, as they no longer had an alternative to attending school. As a result, one can naturally expect that the effect of this law was to raise compulsory education attainment, since children had no alternative to attending school until the age of 16 (see Figure A2 in the Appendix).

Less clear is the expectation of the effects of the reform on post-compulsory education attainment. It could be the case that no changes are observed in post-secondary attainment, as one could argue that the incentives present for children born at the beginning of the year would apply as well at age 16 . In this case, we could

\footnotetext{
${ }^{9}$ Lavy (2015) also finds that increases in education reduce reception rates of disability welfare allowances.

${ }^{10}$ This is consistent with previous research in the epidemiological literature that has reported high mortality levels from aids and abusive drug consumption behavior for young individuals in cohorts born between 1940 and 1970 (see Cleries et al. 2009).
} 
expect that those individuals who would have quit studying at age 14 during the 70 s, would quit at age 16 before attaining the first level of post-compulsory education and remain classified as dropouts. The fall in the numbers of early school leavers would be offset by an increase in the number of children who would not finish post-compulsory secondary education (Bachillerato at that time): the number of dropouts (defined as those who do not attain any level of post-secondary education) would be constant.

On the contrary, it could also be the case that the reform reduced the number of dropouts among individuals born at the beginning of the year. In this case, the reform that prohibited children under the age of 16 to work would not only make those who wanted to leave school early, at age 14, complete compulsory education but would also imply that some of them would attain post-compulsory education. A possible explanation for this temporal inconsistency is that some children are impatient at age 14 and fail to realize that, if they finish compulsory education, their optimal subsequent choice will, in effect, be to complete some post-compulsory education as well. Then, if that is the case, we could argue that, by forcing students to complete compulsory education, the change in the law regulating labor relations in 1980 would also increase post-compulsory attainment. The model we propose in Section 2 elaborates on these ideas and derives some predictions about the potential effects of the reform on post-compulsory educational attainment.

As showed in Figure A3 in the appendix, the minimum age for compulsory education did not change until 1990 (from 14 to 16 years old). Thus, we can be confident that there was no other reform that could threaten our identification analysis.

\section{A model of educational decisions}

We consider a simple model of educational decisions where an individual, characterized by her level of impatience (or present bias) decides whether to continue studying or work. There is a legal minimal working age below which individuals are forced to live on parental support, and a level of education that is compulsory. If individuals attain the minimum working age before attaining compulsory education, they are legally allowed to work and quit school. We call individuals in this situation early school leavers (ESL). If they complete compulsory education, they can decide on a later period whether to complete postcompulsory education and attain higher earnings, or not and remain drop-outs ${ }^{11}$.

ESL perceive on average earnings $y_{0}$. In contrast, while studying, individuals live on family support and consume $s$. There are no savings. Hence consumption in the first period, $c_{0}$ is either $s$ or $y_{0}$. In the second period, ESL continue to earn a low wage (maybe increased by on-the job experience, although for simplicity we leave this out of the model); those who attained compulsory education and quit without attaining postcompulsory education (DO) earn $y_{1}$, and those who continue studying to attain post compulsory education remain on family support consuming s. Finally, in the third period, ESL remain on a low earnings path, $y_{0}$,

\footnotetext{
11 Therefore, we call individuals who have not completed compulsory primary education "early school leavers" whereas "dropouts" include both early school leavers and those who do not complete secondary education (post-compulsory).
} 
DO earn $y_{1}$, and individuals with post-compulsory education attain the earnings $y_{2}$. We assume $y_{0}<y_{1}<y_{2}$, accounting for differences in productivity as well as employment rates. ${ }^{12}$

With hyperbolic discounting, we can introduce a new parameter $\beta<1$ capturing a present bias that characterizes individual preferences and interacts with conventional exponential discounting $\delta$ (O'Donoghue and Rabin, 1999). ${ }^{13}$ Then, individual lifetime utility is

$$
U=U\left(c_{0}\right)+\beta \delta U\left(c_{1}\right)+\beta \delta^{2} U\left(c_{2}\right)
$$

Assume that individuals differ only in $\beta \in\left[\beta_{\min }, \beta_{\max }\right]$, and distributed according to $F(\beta)$ with $F^{\prime}(\beta)=f(\beta)$

We analyze individual decision making by backward induction. At the second stage, those who completed compulsory education get to choose whether to attain post-compulsory education. Note that all individuals who attain the minimum legal working age after completing compulsory education are in this situation. ESL do not make any decision. The utility of an individual with compulsory education can be written at this point

$$
U\left(y_{1}\right)+\beta \delta U\left(y_{1}\right)
$$

if she decides to work, and

$$
U(s)+\beta \delta U\left(y_{2}\right)
$$

if she decides to study.

She will go on studying provided that

$$
U(s)+\beta \delta U\left(y_{2}\right)>U\left(y_{1}\right)+\beta \delta U\left(y_{1}\right)
$$

This allows to derive a threshold of $\beta$ above which individuals attain post-compulsory education and below which they attain only compulsory education, and hence become DO:

$$
\hat{\beta}=\frac{U\left(y_{1}\right)-U(s)}{\delta\left(U\left(y_{2}\right)-U\left(y_{1}\right)\right)}
$$

\footnotetext{
${ }^{12}$ We are modelling the educational decision and assuming that less education implies poorer labor outcomes.

${ }^{13}$ We must allow the conventional discount factor $\delta$ to be larger than one in order to account for the fact that the last period is considerably longer.
} 
At stage 1, only individuals who attain the minimum legal working age before attaining compulsory education get to make the decision to leave school early. The rest of the individuals, if any, get at least the minimum compulsory level of education. We need to differentiate at this point between individuals with a present bias $(\beta<\widehat{\beta})$ who anticipate that they will drop-out after completing compulsory education, and individuals with a future bias $(\beta>\widehat{\beta})$, who anticipate that they will attain post-compulsory education after completing compulsory education.

- Individuals with a present bias: they anticipate that they will not attain post-compulsory education after reaching the compulsory level. They will complete compulsory education if and only if

$$
U(s)+\beta \delta U\left(y_{1}\right)+\beta \delta^{2} U(y 1)_{>} U\left(y_{0}\right)+\beta \delta U\left(y_{0}\right)+\beta \delta^{2} U\left(y_{0}\right)
$$

or

$$
\beta>\frac{U\left(y_{0}\right)-U(s)}{\left(\delta+\delta^{2}\right)\left(U\left(y_{1}\right)-U\left(y_{0}\right)\right)}=\underline{\beta}
$$

Hence, impatient individuals with $\beta<\underline{\beta}$ leave school early and individuals with $\underline{\beta}<\beta<\hat{\beta}$ attain compulsory education.

- Individuals with a future bias: they anticipate that they will attain post-compulsory education after reaching the compulsory level. They will complete compulsory education if and only if

$$
U(s)+\beta \delta U(s)+\beta \delta^{2} U\left(y_{2}\right)_{>} U\left(y_{0}\right)+\beta \delta U\left(y_{0}\right)+\beta \delta^{2} U\left(y_{0}\right)
$$

or

$$
\beta>\frac{U\left(y_{0}\right)-U(s)}{\delta\left(U(s)-U\left(y_{0}\right)\right)+\delta^{2}\left(U\left(y_{2}\right)-U\left(y_{0}\right)\right)}=\bar{\beta}
$$

Patient individuals with $\beta>\bar{\beta}$ attain post-compulsory education, however, if $\widehat{\beta}<\beta<\bar{\beta}$ they will not complete compulsory education. We summarize our findings in the following Figure: 
Individuals who attain minimum working age before completing compulsory education:

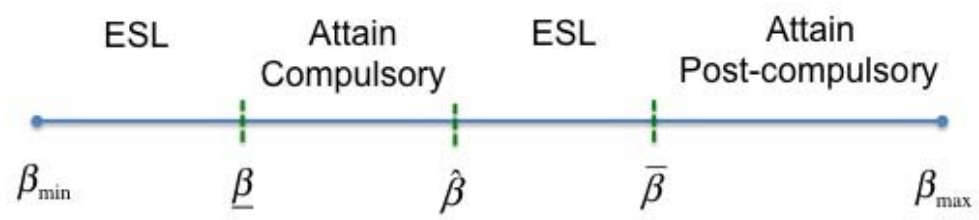

Individuals who attain minimum working age after completing compulsory education:

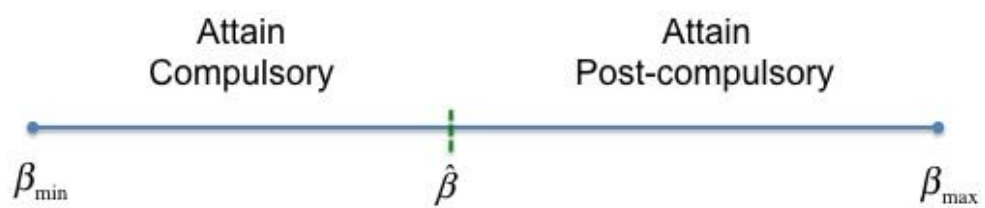

Note that the fact that individuals who attain the minimum working age after completing compulsory education do not leave school early only means that they do not leave school early due to impatience. Other reasons for leaving school early such as those related to ability should not be affected by the reform that is being the object of study.

Summing up, attaining the legal working age before attaining compulsory education allows individuals to leave school early. According to the model, this affects individuals who would only attain the level of compulsory education if they were forced to, but also some individuals who would attain post compulsory education if they were forced to complete compulsory education. A reform that puts off the right to legally work to an age posterior to the age when compulsory education is attained eliminates this incentive, automatically raising the attainment of compulsory education and making it more likely to obtain some postcompulsory education diploma. Thus, the model allows to make two predictions: (a) the reform will reduce the number of early school leavers, consequently increasing compulsory education attainment, and (b) the reform will also increase post-compulsory education attainment.

\section{The key effects of the reform: education and mortality}

\subsection{Effects on educational outcomes}

The first thing that we test is whether the increase in the minimum age of working abolished the incentive for individuals born in the first months of the year to leave school before completing primary education (ESL) as suggested by the theoretical model. Furthermore, we also test the second prediction of the theoretical model which suggests that, if those individuals cannot work before completing primary education, not only will they complete primary education but some of them will also complete secondary education. Therefore, the increase in the minimum working age will also allow a higher proportion of individuals born in the first months of the years to complete secondary education (as compared to the 
situation before the introduction of the reform). Consequently, we should observe a decrease in the proportion of both early school leavers and dropouts (individuals who do not attain post-compulsory education) for individuals born in the first months of the years as a result of the introduction of the reform in 1980.

In order to test these predictions empirically, we use the Spanish Labor Force Survey (LFS) for the waves 2000 until $2013^{14}$. Although the LFS is available from 1976, information on the month of birth, which is a crucial variable for our identification strategy, is only available from 1999. In the Spanish labor force survey, individuals can remain up to six periods. However, we restrict the sample to one observation per individual. We also drop from the sample all immigrants (individuals not born in Spain) as we cannot ensure that they had studied in Spain and, thus, were affected by the reform ${ }^{15}$.

In order to identify the effects of the policy, we will compare two educational outcomes for individuals born in the first/last months of the years before and after the introduction of the reform. In the pre-reform cohorts we include individuals who turned 14 years old before the implementation of the reform (cohorts born between 1957 and 1965). In the post-reform group we include individuals who turned 14 years old after the introduction of the reform (cohorts born between 1967 and 1976) ${ }^{16}$. We drop the cohort born in 1966 because they turn 14 in 1980, the same year of the introduction of the reform.

We define an individual as treated if he/she is born in the first five months of the year, from January until May and he/she is in the control group if he/she was born in the last five months of the year, from August until December.

In this section we analyze the effects of the policy on two main outcomes: the probability of being an early school leaver, defined in the LFS as a person who is illiterate, who has uncompleted primary school or who has been enrolled in labor market integration programs that do not require a primary school degree. The second outcome studied is the probability of being a dropout, defined as an individual who has not completed upper secondary education (has completed at most the first stage of secondary education) ${ }^{17}$.

For each of these two outcomes we apply the following model:

$$
\begin{aligned}
& \text { Outcome }_{i}=\alpha+\beta_{1}\left(\text { BirthYear }_{i}-C\right)+\beta_{2}\left(\text { BirthYear }_{i}-C\right) \mathrm{I}\left(\text { BirthYear }_{i} \geq C\right)+\beta_{3}\left(\text { BirthYear }_{i}-C\right)^{2} \\
& +\beta_{4}\left[\left(\text { BirthYear }_{i}-C\right) \mathrm{I}\left(\text { BirthYear }_{i} \geq C\right)\right]^{2}+\beta_{5} \text { Treat }_{i}+\beta_{6} \mathrm{I}\left(\text { BirthYear }_{i} \geq C\right)_{i}+\beta_{7} \text { Treat }\left(\text { BirthYear }_{i} \geq C\right)_{i} \\
& +\beta_{9} \text { UnemRateEn try }_{j}+\beta_{10} \text { Gender }_{i}+\operatorname{Re}_{\text {gionFE }}+\varepsilon_{i}
\end{aligned}
$$

\footnotetext{
${ }^{14}$ The Spanish Labor Force Survey is called "Encuesta de Población Activa".

${ }^{15}$ The big immigration boom in Spain occurred during the first half of the 2000's so that those individuals were not affected by the reform introduced in 1980 .

${ }^{16}$ Therefore, in our sample of the LFS (2000-2013) those cohorts were aged between 35 and 57 for the pre-reform cohort and between 24 and 46 for the post-reform cohort so that they are no longer studying neither primary nor secondary education.

${ }^{17}$ For both outcomes we also condition on not being a student at the time of the survey in 2000-2013. However, if we do not include this restriction in the definition, results are exactly the same as there are few individuals that are still studying at these ages.
} 
Where " $C$ " is the cohort born in 1966 (individuals that turn 14 in the year of the implementation of the reform; 1980). The model includes a pre-reform and post-reform linear and quadratic trend as well as some controls for gender, province fixed effects and the province unemployment rate at age 14 (52 provinces). Therefore, $\beta_{7}$ identifies the effect of the policy change. We estimate an alternative specification of this model with cohort dummies instead of pre and post-reform trends and the results obtained are the same. Finally, we cluster the standard errors at the cohort level in all our specifications ${ }^{18}$.

Figures 3, 4 and 5 plot the probability of being an early school leaver and a high-school dropout for each cohort born from 1957 until 1976. The figures differentiate between individuals born at the beginning of the year and individuals born in the last months of the year and show both the raw data in dots as well as the predictions from the estimation model explained above. The left panel of Figure 3 shows that, before the reform, individuals born during the first months of the year exhibited a higher probability of being an early school leaver as compared to individuals born in the last months of the year. This gap is closed once the reform is introduced in 1980 and the age for minimum work is increased to 16 years old. Therefore, after the reform, individuals born in the beginning and end of the year have the same probability of being early school leavers. This seems like an expected result as the option of working is no longer available at age 14, which deletes all incentives to drop out before completing primary education in order to find a job. As shown in Table 1, the drop in the probability of being an early school leaver due to the policy implementation corresponds to 0.65 percentage points for men and to 0.37 for women. However, when we look at the right panel of Figure 3, we observe that, not only the probability of dropping out from primary education is affected but also the probability of dropping out before completing secondary education is affected by the policy change. Thus, as predicted by the theoretical model, forcing students to complete primary education provides an incentive to part of those students to complete also secondary education. Therefore, the reform also reduced the probability of being a dropout (not completing secondary education) for individuals born in the first months of the year.

The results of the estimation in Table 2 suggests that the probability of being a dropout decreased by 1.8 percentage points for men and by 1 percentage point for women due to the increase in the minimum working age. We observe that the results are significant for both men and women but the effects on the probability of being a dropout are stronger for men. This can be explained by the fact that in Spain low educated men have more opportunities to work in sectors like construction than low educated women so that the incentives to drop out before the reform are higher for men as shown by the coefficient on the treatment variable. Figures 4 and 5 plot the differential effect of the policy for men and women.

In order to get a clearer idea of the size of these effects, we perform a back-of-the-envelope calculation of the absolute number of individuals affected by the reform by taking into account the number of treated

\footnotetext{
${ }^{18}$ We have also estimated the same model with the data collapsed at the level of cohort, trimester, treatment status and region and we have included fixed effects for region, cohort and trimester (calendar time) and the results are exactly the same as those presented here with individual data.
} 
men/women in the affected cohorts. We find that the reform reduced the number of ESL in the first postreform cohort (1967) in 862 men and 408 women whereas the number of dropouts decreased by 2586 for men and 1361 for women. As the number of ESL in the last pre-reform cohort, 1965, was 3895 for treated men and 3701 for treated women the effect of the reform implies a decrease in ESL by $22 \%$ for men and 11\% for women. The number of dropouts in 1965 was 69709 for treated men and 66411 for treated women. Therefore, the reform decreased dropouts by $3.7 \%$ for men and about $2 \%$ for women. If we extrapolate this result taking into account the first 10 post-reform cohorts (from 1967 to 1976) the reduction in ESL (dropouts) amounted to 8594 (25782) men and 4053 (13512) women.

One potential concern with our specification is that individuals born in January and December are typically quite different in several dimensions as reported in several papers (See, for example, Bound and Jaeger: 2000 or Buckle and Hungerman; 2013). Even if these differences should cancel out when doing the beforeafter comparison and, therefore, shouldn't affect our results, we try to address the potential remaining doubts of comparing too different individuals by dropping from our sample individuals born in the first and last two months of each year. We call this the "reduced sample" where we compare the outcomes of individuals born in months 3, 4 and 5 with those born in months 8,9 and 10. Table 2 reports the results for the probability of being an early school leaver and a dropout for this reduced sample. As it can be seen, the estimated coefficients are very similar to those in the complete sample although slightly lower for early school leavers (for both men and women) and slightly higher for dropouts (also for both genders).

Using the same reasoning provided by the theoretical model of section 2, we could also argue that the reform would not only provide incentives for individuals to finish both compulsory and secondary education but, at least some of them, could also continue studying into tertiary education. In order to check the extent of these changes in incentives, we perform the same estimation for the probability of having studied at the university level (having completed at least three courses of any of the university degrees). Table 3 reports the results of this regression and we can see that, for both the complete and the reduced sample, the effects of the reform on the probability of studying at the university level are positive and significant for men. The coefficients for women go in the same direction pointing towards an increase in the probability of studying at the university level as a result of the reform but the effects are not significant.

Finally, as a last robustness check of the effects of the reform on educational outcomes, we report in Figure A4 and Table A1 of the appendix the results for the same dependent variables using an alternative database: a five percent representative sample of the 2001 Census data (from the National Institute of Statistics). The results obtained from this analysis have to be considered with caution as we cannot construct the exact same definitions for ESL and Dropout with the Census data than with the Labor Force Survey. However, even with this limitation in mind, the preliminary results point to a strong effect of the reform on the probability of being an ESL or a Dropout for treated individuals that fully compensates the differences we have detected before the reform. 


\subsection{Effects of education on mortality}

After proving that the reform increased the level of education for both men and women in Spain, we next explore whether education has, in turn, an impact on mortality. We use the reform as an instrument for higher levels of education and, thus, we compare the probability of dying for individuals born in the first/last months of the year before and after the reform. As suggested by some papers in the literature, if the effects of the reform in terms of increased education are strong enough, we could also expect to find differences in mortality rates of affected workers (Lleras-Muney, 2005; Clark and Royer, 2013).

We use death register data obtained from the National Institute of Statistics containing information on all deaths in Spain from 1975 until 2012. For each death occurred in that period, we have information on gender, nationality and month and year of birth of the person. As before, we drop immigrants from the sample and collapse the individual data at the level of the cohort and calendar year for the treated and control groups. Therefore, we estimate the following model,

$$
\begin{aligned}
& \text { Outcome }_{j t}=\alpha+\beta_{1} \text { Treat }+\beta_{2} \mathrm{I}(\text { BirthYear } \geq C)_{j t}++\beta_{3} \text { TreatI }(\text { BirthYear } \geq C)_{j t}+ \\
& + \text { CohortFE }_{j}+\text { CalendarTimeFE } \\
& t
\end{aligned}
$$

where the outcome of interest is the death rate per cohort and calendar year as defined by the number of deaths divided by the population for each cohort of treated and control (and multiplied by 1000) ${ }^{19}$. In the above model, $\beta_{3}$ captures the effect of the reform after controlling for cohort and calendar time fixed effects.

As we have register data for the years 1975 to 2012 and we want to compare the cohorts of 1975-2012, taking into account that mortality is age-specific, we restrict the sample to include deaths occurred between the ages of 15 and 40 years old (see Figure A5 in the Appendix section).

The regression results are reported in Table 4 both for the full and the reduced sample. The coefficients for the two samples go in the same direction although the significance levels are higher when we use the reduced sample and compare more similar individuals. For both men and women before the reform there is a significantly higher mortality rate for individuals born at the beginning of the year although this gap is only reduced for men after the introduction of the reform. The coefficient for women not only is non-significant but it also has an unexpected positive sign suggesting that, if anything, the reform may have increased the mortality rate of women born at the beginning of the year (and acquiring higher levels of education). In order to explore these results further, we split the mortality rate into a short-term (ages 15-25) and a longerterm effect (26-40). In Table 5 we can see that, before the reform both men and women born in the first

\footnotetext{
${ }^{19}$ In the denominator, we use data on the population of each cohort recorded at the time of being born. We do not use population of each cohort recorded at each calendar year because we are interested in the fraction of each initial cohort that dies every year.
} 
months of the year had a higher mortality rate than those born at the end of the year. After the reform, these gaps in mortality rates are completely closed for young men and almost so for young women. However, when looking at the effects of the reform in the longer-run, we see that the reform did not have an impact on mortality rates of affected men in the ages 26-40 while it significantly increased mortality rates of affected women in their middle-ages, which is an unexpected result. A graphical representation of the age-based results can be found in Figure 6 for men and Figure 7 for women.

If we perform an estimation of the number of affected men and women taking into account the size of the cohorts, we find that the reform decreased the number of men that died in the ages of 15-25 by 129 and the number of women by 54 for the first post reform cohort ${ }^{20}$. As the number of deaths at ages 15-25 in the last pre-reform cohort, 1965, was 3551 for treated men and 1084 for treated women, the effect of the reform implies a reduction in the probability of dying at ages $15-25$ by $3.6 \%$ for men and by $5 \%$ for women. If we extrapolate the result to the first 10 post reform cohorts we get a decrease in mortality of 1289 men and 540 women.

On the other hand, for ages 26-40 the reform did not have any significant impact on men but it increased the number of women that die in the first post reform cohort by 80 . As the number of deaths at ages $26-40$ in the last pre-reform cohort, 1965, was 2676 for treated women, the effect of the reform implies an increase in the probability of dying at ages $26-40$ by $3 \%$ for women. If we take into account the first 10 post reform cohorts, the number of women that die due to the reform raises to 794 .

Before trying to disentangle the potential channels that lead to the reduction in mortality rates for young men and women and the increase in mortality rates for middle-aged women, we perform a robustness check of these mortality results using a different database. Table A2 in the appendix shows the estimates of the probability of dying using an administrative database from the Social Security administration which includes (a 4\% random sample of) everybody that had a relationship of at least one day with the Social Security administration (working, receiving unemployment benefits or any other kind of Social Security benefits like old-age or disability) in 2007-2013. We include cohorts from 1958 to 1974 and estimate the probability of dying in 2007-2013 conditional on being in the sample (that is, having had a relationship with the Social Security administration for at least one day in 2007-2013). Again, we see that the effects of the reform are negative and significant for men and positive (although not significant) for women. That is, the reform significantly reduces (basically eliminates) the previous differences in mortality for men and has a positive but not significant effect for women. Although these results point to the same findings than the results using register data on mortality, they have to be taken with caution as there might be sample selection problems. These sample selection problems are presumably more important for the case of women, which may have a

\footnotetext{
${ }^{20}$ The reform caused a reduction in mortality for young men by 0.09 pp per year per 1000 treated men. For the cohort of 1967 , we multiply the effect of the reform by 10 ages (15 to 25$)$ and by the number of treated individuals in that cohort and we divide it by 1000 .
} 
more interrupted contributory career. Furthermore, if the reform affected the probability of working and, thus, contributing to the Social Security administration the pre and post reform samples are not comparable as they are endogenously affected by the reform.

\section{Disentangling the channels}

\subsection{The effects of education on labor market outcomes}

One plausible channel through which education can have an impact on mortality is the labor market. The literature on the topic has typically found a positive effect of education on labor market outcomes which can be later on translated into lower mortality risk. After proving that the increase in education had a positive effect on short-term mortality for both men and women but a negative effect on women mortality in the long-run, in this section we assess whether part of this effect can be explained by changes in the labor market.

Therefore, we now focus our attention on the potential effects of increasing the minimum working age on long-term labor market outcomes of affected workers. In principle, it seems reasonable to expect that an increase in the minimum working age that raised the level of education of affected workers will have longterm impacts on employment and earnings. To explore this hypothesis, we first use the Labor Force Survey for the waves 2000-2013 (as before) and collapse the individual data at the level of trimester, cohort and treatment status $^{21,22}$. Therefore, the model includes cohort and calendar time fixed effects (for each trimester) to control for any change in economic or legal conditions. As the LFS does not have information on wages, the outcomes analyzed are the probability of working, the probability of working in the construction sector (a very large sector in the Spanish economy from the 80's and until the recent crisis), the probability of having a low skill job and the probability of being inactive (which may be important for the case of women).

As results for the full and reduced sample are quite similar, we only report the outcomes of the estimation for the reduced sample. Table 6 reports the labor market results for men and women in our sample. For the case of men, we find a negative difference in the probability of having a job before the reform between individuals born at the beginning or the end of the year that is significantly offset once the reform is introduced. A similar picture can be observed for the probability of working in the construction sector as well as for the probability of being a low-skilled worker; before the reform individuals born at the begin of the year had a higher probability of working in the construction sector (as they had a higher probability of being an ESL and a dropout). This difference disappears once the reform is introduced. The reform, however, has no significant effect on the probability of being inactive for men, which can be interpreted as

\footnotetext{
${ }^{21}$ The mean cell-size is 196.8 observations and there are only two cells with less than 100 observations ( 89 is the minimum).

${ }^{22}$ Note that, as explained above, we cannot use previous waves of the LFS as the month of birth is not reported until the wave of 2000 .
} 
the reform having an impact on changes between employment and unemployment as well as inside the employment category from low-skilled jobs to higher skill occupations.

This is a slightly different picture than the case of women. The last 4 columns of Table 6 report the results of the labor market effects of the reform on women. We can see that, before the reform, the difference in employment probabilities between women born at the beginning and at the end of the year is much stronger than in the case of men. Thus, the labor market effect of the reform, which abolishes these pre-reform differences, is also stronger than the effect for men. Furthermore, we do not see any impact of the reform on the probability of working in the construction sector or on the probability of being a low-skilled worker suggesting that the increase in the probability of working did not imply changes in the composition of employment. In the last column of Table 6 we can see that the increase in employment comes entirely from a decrease in the probability of being inactive for treated women. Before the reform, women born at the beginning of the year had a greater probability of being inactive and this difference is abolished once the reform is introduced. This last result can help explain why we do not find an effect of the reform on the skill level of employed women as before the reform low educated women were inactive (while low educated men were employed).

In order to explore the effect on wages we use administrative data from the "Muestra Continua de Vidas Laborales" (MCVL). As explained above, the MCVL is an administrative dataset from the Spanish Social Security administration. We have information on the employment status, the probability of working under a temporary contract and wages by quarter from 2007 to $2013^{23}$ as well as information on the first date in which the individual found a job and the accumulated labor market experience. We collapse the individual data at the cohort, region and quarter level (28 quarters) for the control and treatment groups and estimate a similar model to the one presented for the LFS. Standard errors are clustered at the cohort level. ${ }^{24}$

Table 7 presents the results for men and we can see that, before the reform, there is a significant difference in the probability of working as well as in the logarithm of wages between individuals born at the begin and end of the year. Although these differences are reduced after the reform, these coefficients are not significant. We do not observe any effect of the reform on accumulated labor market experience for men born in the beginning and end of the year. This finding is consistent with the LFS results that, for the case of men, pointed towards an effect of the reform in upgrading the skill level of workers while raising in a small proportion their probability of working.

On the other hand, in the third column of Table 7 we can see that the reform reduced the probability of having a temporary contract for men born in the first months of the year. Similarly, the last column of Table

\footnotetext{
${ }^{23}$ The MCVL is not a truly panel database but we have constructed a panel version of the data combining waves from 2007 to 2013.

${ }^{24}$ We also drop immigrants for the reason explained above.
} 
7 shows that before the reform, men born at the beginning of the year entered the labor market 140 days before men born at the end of the year. Once the reform is introduced, this difference is reduced in 46 days.

The results for women are shown in Table 8. We do not find a significant effect of the reform on the probability of working, having a temporary contract or on wages although the coefficients have the expected sign. It has to be noted that the differential impact of the reform in employment probabilities when using the LFS or the MCVL is mainly attributable to two factors: first, the samples in the two datasets are different as in the MCVL only individuals that have contributed to the system between 2007 and 2013 are included and, second, the MCVL only includes information during the crisis period while the LFS includes labor market information on both pre and post crisis.

As it can be seen in the fourth column of Table 8, we do find that treated women accumulated less number of days in employment before the reform and this difference is offset once the reform is implemented. Similarly, the last column of Table 8 shows that, before the reform, women born at the beginning of the year entered the labor market 143 days before women born at the end of the year. Once the reform is introduced, this difference is reduced in 80 days.

Thus, for both men and women we report an impact of the reform in increasing the probability of working (stronger effect for women) as well as on delaying the date of the first labor market experience. However, for men the reform shows also an impact on the composition of employment (increase the skill level of workers and improve the employment conditions (fewer temporary contracts)) while for women the impact seems to come from a transition from inactivity to employment without a significant effect on the skill level of affected women.

Finally, we provide a quantification of the effects of the reform on labor market outcomes. We estimate that the reform increased the number of men that work in 862 and the number of women that work in 1837 for the first post reform cohort ${ }^{25}$. Similarly, the number of inactive women decreased by 1796 while the number of men working in the construction (low skill) sector decreased in 1149 (2730) individuals. If we estimate the effect of the reform for the first 10 cohorts, we find that the number of men and women that work increased in 8594 and 18241, respectively. The number of inactive women decreased by 17836 and the number of men working in the construction (low skill) sector decreased by 11458 (27214) as a result of the reform.

\subsection{Does work kill or saves lives?}

This heterogeneous labor market effects could help us explain the impact of the reform on mortality. For example, it seems reasonable to suggest that having a better job, in terms of having an occupation with a

\footnotetext{
${ }^{25}$ For men, the increase in the probability of working due to the reform is of $0.6 \mathrm{pp}$ (as the rate is multiplied by 100 ); thus, for the cohort of 1967 we multiply the effect of the reform by the number of treated individuals in that cohort in order to get the effect of the reform in absolute numbers of affected individuals.
} 
higher skill level and a more stable type of contract, could lead to a lower incidence of working accidents. In a similar way, we can expect that the probability of suffering from a permanent disabling condition (either a job related accident or a common illness) is going to be higher for low educated, low skilled individuals.

Thus, in what follows we explore the incidence of working accidents as well as the inflow into permanent disability benefits for individuals born at the beginning and end of the year before and after the reform.

We first use register data for all working accidents occurred in Spain from 1988 until 2013. In order to include individuals of the same ages, we restrict the sample to the cohorts of 1960-1972 and ages 28-41. We collapse the data by calendar year and cohort for the treatment and control groups and divide it by the population for each cohort of treated and control individuals. ${ }^{26}$ Table 9 reports the results of the effects of the policy for all working accidents as well as for deadly working accidents for the reduced sample.

In the first two columns of Table 9 we can see that the reform decreased the probability of suffering a working as well as a deadly working accident for young men. The effect is much stronger and significant when we consider all types of working accidents than when we only consider those accidents that end up with the dead of the injured worker (the coefficient is not significant in this case) ${ }^{27}$. For women (columns 3 and 4), we find a smaller and significant reduction in the total number of working accidents although the coefficient for deadly working accidents is now positive but not significant. Although the coefficient for deadly working accidents is not significant, its positive sign is consistent with the reported increase in mortality rates of middle-aged women.

As showed above, we find the strongest decrease in mortality rates for the age group of 15-25 years old. Although we do not have data on working accidents before the age of 28 and, thus, we cannot analyze the effects of the reform on working accidents of this young group of workers, we repeat the estimation for the youngest group of workers that we have in our working accidents data, which is from 28 to 35 years old. We can see in columns 5 and 6 of Table 9 that, if we restrict the analysis to the youngest age group (28-35) of men, the effect of the reform is much stronger although the coefficient is again only significant when we include all types of working accidents. These results point to a stronger incidence of the reform in reducing working accidents for the youngest group of workers and could explain, to some extent, the decrease in mortality rates of young men.

The effects of the reform on non-deadly working accidents could also be translated into a lower incidence of permanent disability benefits for affected workers. Thus, we use the MCVL database (described above) to explore the effects of the reform on disability benefits. The MCVL contains information on individuals

\footnotetext{
${ }^{26}$ We use the same model than with the mortality register data.

27 There is also some literature pointing to the reduction in mortality of young men and women due to the reduction in traffic accidents (Saiz-Sanchez et al. 1999; Gine 1992; Puig et al. 2002; Gomez-Redondo et al. 2005; Serra et al. 2006; Puig et al. 2005). Although we believe that this could, indeed, be a very plausible channel we do not have data on traffic accidents by month of birth. Furthermore, we were only able to obtain data on traffic accidents from 1993.
} 
receiving permanent disability benefits from 1990 until 2011. In order to control for business cycle conditions during this period, we collapse this information at the level of the cohort and calendar time for the treated and control groups. The outcome of interest is the inflow rate as defined by the number of new disability beneficiaries each year divided by the population for each cohort and treatment status multiplied by 1000 .

Table 10 shows the existence of a gap in the inflow rates into permanent disability benefits between individuals born at the beginning and end of the year before the implementation of the policy. This gap disappears for the cohorts that turn 14 after the implementation of the policy although the effects are not significant. $^{28}$

\subsection{More education better health behaviors?}

The second channel that we propose through which education can have an impact on mortality is health behaviors. The literature has usually found a positive impact of education on health behaviors, which can be later on translated into lower mortality rates. Therefore, after providing evidence of the effect of the reform on labor market participation and working accidents, we further explore the existence of any changes in health behaviors that could further explain the decrease in young individual's mortality rates and/or the increase in middle-age women mortality rates.

In order to do that, we first focus on the 2006 wave of the Spanish National Health Survey. This survey has 8 waves starting from 1987 until 2011. However, only the 2006 wave has information on the month of birth, which is crucial for our identification strategy. As before, we analyze the effects of the reform by comparing health behavior outcomes of individuals born at the beginning and end of the year before and after the reform. We include cohorts of 1956-1976 and show the results separately for men and women for the reduced sample. Table 11 reports the effects of the reform on several outcomes for men: a number of these outcomes are directly related to health behaviors such as the probability of smoking regularly or smoking every day and the probability of drinking beer every day. Some other outcomes are related to the consequences of these health behaviors, such as the probability of having high blood pressure, the probability of suffering from bronchitis or the probability of suffering diabetes. The results in Table 11 show that most of the coefficients are not significant. Therefore, our results show that the reform did not have any significant effect on health behavior for affected men. This result is consistent with the insignificant effect of the reform on middle-age mortality rates for men.

Table 12 shows the results of the same outcomes for the case of women. As it can be seen in the first two columns, before the reform women born at the beginning of the year had a significant lower probability of

\footnotetext{
${ }^{28}$ It has to be noted that disability can be accessed due to a working accident or a common illness. As we have seen in the previous paragraph that the incidence of working accidents is reduced for treated women, the increase in disability benefits for treated women as a result of the reform should be explained by an increase in common illness.
} 
having high blood pressure and bronchitis ${ }^{29}$. Once the reform is implemented, these differences are significantly reduced. A similar pattern is found for the probability of having diabetes although the coefficients are not significant. Moreover, in the fifth and sixth columns of Table 12 we can also see that the reform significantly increased the probability of smoking regularly and drinking beer every day for affected women.

As before, if we quantify these effects taking into account the size of the post-reform cohorts, we estimate that, for the first post reform cohort, 5171 more women suffered high blood pressure, 6124 more women had bronchitis, 8030 more women smoked regularly and 3810 more women drunk beer on a daily basis. ${ }^{30}$

Therefore, these results which go on the opposite direction of the literature on the topic as they show that the increase in education and labor market participation of affected women lead to the adoption of worse health behaviors, in particular drinking and smoking, which resulted in an increased incidence of high blood pressure and bronchitis. These unexpected results go in line with the observed increase in mortality rates of middle-aged women affected by the reform.

One possible explanation of these effect is the fact the women in these generations (about 45 years of age currently), that were growing during the Spanish early post Franco year, participated in a process of gender equalization, by continuously increasing education and labor market attachment. For them, access and social acceptance of bad habits was much easier than it used to be for previous cohorts.

In fact, although there is not much evidence of this effect for Spanish women, a recent paper by Bilal et al. (2015) shows that the rapid decline in gender inequality in Spain from the 1960's to the 2010's is highly inversely correlated (-0.99) with a rising female-to-male smoking ratio. The authors calculate the inequality index based on three dimensions (reproductive health, empowerment and labor market). They also show that this convergence in smoking rates between men and women in Spain is stronger for women with high education levels.

Tables 13 and 14 explore this result further by analyzing whether the increase in bad health behaviors in treated women was also translated into increases in the number of hospitalizations related to these health behaviors. We use register data on hospitalizations from 1980 to 2013 and explore the probability of being hospitalized due to substance abuse, respiratory problems, mental illness or injuries for young (17-25) and middle aged (26-44) men and women. In Table 13 we can see that, although most of the coefficients for young men and women are negative, the only significant result points to a reduction in the percentage of hospitalizations due to respiratory problems for young women. The coefficient for men is also negative but not significant. These results are consistent with the reported reduction in mortality for young men and

\footnotetext{
${ }^{29}$ The reform reduced the probability of treated women having high blood pressure (bronchitis) by 3.8 (4.5) percentage points.

${ }^{30}$ If we consider the first 10 post reform cohorts, we estimate that 51346 more women suffered from high blood pressure, 60805 more women had bronchitis, 79722 more women smoked regularly and 37834 more women drank beer.
} 
women. Table 14 shows the results for middle-age individuals (26-44). Again, the only significant result is an increase in the percentage of hospitalizations due to respiratory problems for treated women after the reform, which is consistent with the increase in mortality rates of middle-aged women. We also find a reduction in the percentage of hospitalizations due to injuries for middle age men and women (although the coefficient is only significant for women) which is consistent with the reduction in the number of working accidents as a result of the reform.

Finally, Table 15 presents further evidence on the positive effects of education on health behavior for men which can partly explain the observed decrease in mortality rates. The database used is the Survey on Health and Sexual Habits developed by the National Institute of Statistics and implemented in 2003. We can see in the first columns of Table 15 that, before the reform, men born at the beginning of the year have a significantly higher probability of having tried injectable drugs. This difference is significantly reduced once the reform is implemented. We estimate that the reform reduced the number of men that had tried injectable drugs in 4167 in the first post reform cohort and in 41537 for the first 10 post reform cohorts. The second column shows that this effect is not significant for the case of women. This is consistent with the findings from the epidemiological literature that report an increase in mortality due to AIDS and abusive drug consumption behavior at young ages for the cohorts of 1940-1970 (Garcia et al. 1999; Instituto de Salud Carlos III 2007; Gomez-Redondo et al. 2005; Ribes et al. 2004; Cleries et al. 2009).

\section{Conclusion}

In this paper we have explored the effects of a reform introduced in Spain in 1980 which increased the legal working age from 14 to 16 years old while the compulsory schooling age remained constant at 14 years. We have shown that the reform eliminates the differential incentives to quit school before even completing the compulsory schooling level for those born early in the year, thereby increasing the incentives to accumulate education.

Our results show that the increase in the age of compulsory education decreased the number of early school leavers (not finishing primary education) in 8594 men and 4053 women born at the begin of the year in the first ten post reform cohorts. At the same time, the reform also decreased the number of individuals born in the first months of the year not finishing secondary education (dropout) in 25782 men and 13512 women in the first ten post reform cohorts. Therefore, the reform closed the previous gap in early school leavers and dropouts for individuals born at the beginning/end of the year. However, given the important gender differences existing at that time (in several dimensions: behavior, labor market access, etc...), the lifetime implications for men and women proof to be very different.

In terms of labor market outcomes, we report an impact of the reform in increasing the probability of working for both men and women, although the effect is stronger for women. Also the reform delayed the date of the first labor market experience. However, for men, the labor market impact seems to have rather 
affected the composition of employment (increasing the skill level of workers and improving the employment conditions, with fewer temporary contracts). In contrast, for women, the labor market impact comes from a transition from inactivity to employment, without a significant effect on the skill level of affected women.

In terms of mortality, the reform reduced the previous gap in mortality rates of young men and women born at the beginning/end of the year. However, it increased the mortality rate of middle-age treated women. We estimate that the reform saved 1289 treated men and 540 treated women aged 15-25 in the first ten post reform cohorts but it increased mortality in 794 treated women between the ages of 26 and 40. In line with Brunello (2015), who finds sizeable long term effects, as long as we revisit the results incorporating older ages, the total lifetime effects can be considerably larger.

What factors help explain these changes in the mortality differences between those born early and late in the year? We find that one channel that lead the increase in education to reduce mortality for young individuals is through a reduction in the incidence of working accidents as a result of the positive labor market effects of education. Another channel is the reduction in disability and in the consumption of injectable drugs for young men who attain higher levels of education as a result of the reform ${ }^{31,32}$.

With respect to the gender differentials, we provide evidence that the increase in female employment that resulted from raising female education levels deteriorated the health habits and increased the incidence of habit-related diseases for these women. Ultimately, this is translated into increases in mortality for middle aged women. Together, these results help explain the closing age gap in life expectancy between women and men in Spain, that has been reduced by 1.5 years in the last twenty years. Although we have reported in this paper both positive (labor market) as well as negative (mortality and health) effects of the reform on affected women, it is not clear how these women would evaluate and value this gains and losses. Thus, in order to understand whether the positive effects of the reform outweigh the negative ones based on self-reported information of women affected by the reform, we analyze the impact of the reform on subjective wellbeing using the $5^{\text {th }}$ wave of the World Values Survey (2007). As shown in Table 16, treated women after the reform report significantly lower levels of happiness. ${ }^{33}$ As expected, the results for men are not significant.

The results presented so far describe the within cohort effects of the increase in the minimum working age on many outcome. As the reform may also have between cohort effects we have also performed a beforeafter comparison. The results seem to suggest that only men are positively affected by the reform by accumulating a higher educational level and reduced mortality. Different cohorts of women seem to be less

\footnotetext{
${ }^{31}$ Lavy (2015) also finds that increases in education reduce reception rates of disability welfare allowances.

${ }^{32}$ This is consistent with previous research in the epidemiological literature that has reported high mortality levels from aids and abusive drug consumption behavior for young individuals in cohorts born between 1940 and 1970 (see Cleries et al. 2009)

${ }^{33}$ Only the $5^{\text {th }}$ wave of the World Value Survey can be used as the month of birth is not reported in any of the waves of the survey and treatment and control status is assigned by taking into account age, year of birth and month of the interview. However, only the $5^{\text {th }}$ wave is implemented in July, which allows us to perform a clear categorization between treatment and control groups.
} 
by the reform and only the within cohort results proof to be significant for women ${ }^{34}$. However, as we have mentioned in the introduction, the 80's was a very turbulent period in Spain and many reforms and social changes were taking place quite rapidly after the 40 years of very stable dictatorial regime (for example, divorce and abortion were legalized around that period). Therefore, we are not confident of this identification strategy in the current setting as the effect of any of the other reforms could be picked up in the before-after results.

${ }^{34}$ These results are available upon request from the authors. 


\section{REFERENCES}

Anderberg, D. and Zhu, Y., 2014. "What a difference a term makes: the effect of educational attainment on marital outcomes in the UK", Journal of Population Economics, vol.27(2), pages 387-419.

Bilal, U., Beltrán P., Fernández E., Navas-Acien A., Bolumar F., Franco M., 2015. "Gender inequality and smoking: a theory-driven approach to smoking gender differences in Spain", Tobacco Control, 0, pages 1-6.

Bound, J. and Jaeger, D., 2000. "Do compulsory school attendance laws alone explain the association between quarter of birth and earnings?, Worker Well-being, 19, pages 83-108.

Brunello, G., Weber, G., Weiss, C. 2015. "Books are forever: early life conditions, education and lifetime earnings". The Economic Journal, Forthcoming.

Buckles, K.S., and Hungerman, M., 2013. "Season of birth and later outcomes: Old questions, new answers", Review of Economics and Statistics, 95(3), pages 711-724.

Clark, D. and Martorell, P., 2014 "The Signaling Value of a High School Diploma", Journal of Political Economy, vol.122(2), pages 282-318.

Clark, D. and Royer, H., 2013. "The Effect of Education on Adult Mortality and Health: Evidence from Britain”, American Economic Review, vol. 103(6), pages 2087-2120.

Cleries, R., Martinez, J.M., Valls, J., Pareja, L., Esteban, L., Gispert, R., Moreno, V., Ribes, J., Borràs, J.M., 2009. "Life expectancy and age-period-cohort effects: analysis and projections of mortality in Spain between 1977 and 2016", Public Health, vol.123(2), pages 156-162.

Dee, T. S., 2004. "Are there civic returns to education?", Journal of Public Economics, vol.88(9-10), pages 1697-1720.

Dickson, M. and Harmon, C., 2011. "Economic returns to education: What We Know, What We Don't Know, and Where We Are Going-Some brief pointers", Economics of Education Review, vol.30(6), pages 1118-1122.

Edmonds, E.V. and Shrestha, M., 2014. "You get what you pay for: Schooling incentives and child labor", Journal of Development Economics, vol.111(C), pages 196-211.

Felgueroso, F., Gutiérrez-Domènech, M. and Jiménez-Martín, S., 2014. "Dropout trends and educational reforms: the role of the LOGSE in Spain”, IZA Journal of Labor Policy, vol.3(1), pages 1-24.

García, D.O., Cayla, J.A., Brugal, M.T., Galdos, H., Jansa, J.M. and Clos, R., 1999. "The evolution of AIDS mortality and survival in Barcelona (1981-1997)”, Medicina Clínica, vol.113, pages 169-170.

Gine, J.M., 1992. "Mortality by traffic accidents in Catalonia and in other autonomous communities", Gaceta Sanitaria, vol.6 (31), pages 164-169.

Gómez-Redondo, R. and Boe, C., 2005. "Decomposition analysis of Spanish life expectancy at birth: evolution and changes in the components by sex and age", Demographic Research, vol.13, pages 521-546.

Haveman, R.H. and Wolfe, B.L., 1984. "Schooling and Economic Well-Being: The Role of Nonmarkert Effects", Journal of Human Resources, vol.19(3), pages 377-407.

Heckman, J., Humphries, J.E., Veramendi, G. and Urzúa, S., 2014. "Education, health and wages”, NBER Working Paper \#19971. Cambridge, Massachusetts: National Bureau of Economic Research. 
Instituto de Salud Carlos III, 2007. "Mortalidad en España y Comunidades Autónomas”. Centro Nacional de Epidemiologia, Madrid.

Jaeger, D.A. and Page, M.E., 1996. "Degrees Matter: New Evidence on Sheepsskin Effects in the Returns to Education", The Review of Economics and Statistics, vol.78(4), pages 733-740.

Lavy, V., 2015. "Long Run Effects of Free School Choice: College Attainment, Employment, Earnings, and Social Outcomes at Adulthood", NBER Working Paper \#20843. Cambridge, Massachusetts: National Bureau of Economic Research.

Lleras-Muney, A., 2005. "The Relationship Between Education and Adult Mortality in the U.S.", Review of Economic Studies, vol.72(1), pages 189-221.

Lochner, L., 2004. "Education, Work, And Crime: A Human Capital Approach", International Economic Review, vol. 45(3), pages 811-843.

Milligan, K., Moretti, E. and Oreopoulos, P., 2004. "Does education improve citizenship? Evidence from the United States and the United Kingdom”, Journal of Public Economics, vol.88(9-10), pages 1667-1695.

Oreopoulos, P., 2006. "The compelling effects of compulsory schooling: evidence from Canada", Canadian Journal of Economics, vol.39(1), pages 22-52.

Puig, X., Lopez-Abente, G., Gispert, R., Freitas, A., Puigdefabregas, A., 2005. Departament de Salut, Generalitat de Catalunya.

Puig, X., Gispert, R., Puigdefabregas, A., 2002. "Mortalitat per accidents de transit. Catalunya 1983-1998", Butlletí Epidemiologic de Catalunya, vol.6, pages 73-76.

Ribes, J., Cleries, R., Borras, J., Galceran, J., Bosch, F.X., 2004. "Time trends in incidence and mortality for chronic liver disease and liver cancer in the interval 1980-1997 in Catalonia", European Journal of Gastroenterology and Hepatology, vol.16 (9), pages 865-872.

Saiz-Sanchez, C., Bautista-Rentero, D., Corella-Piquer, D., Cortina-Birlanga, S., Gonzalez-Arraez, J.I., 1999. "Age-period-cohort analysis of mortality caused by traffic accidents in Spain", Salud Pública de Mexico Journal, vol.41(3), pages 170-176.

Serra, I., Gispert, R., Puig, X., Torné, M.M., Puigdefabregas, A., 2006. "Impacte de l'edat i les causes de mort en els canvis de l'esperança de vida. Catalunya 1987-2002". Mimeo. 
FIGURES AND TABLES

Figure 1. Labor force participation and employment by year of birth and gender. 1946-1979

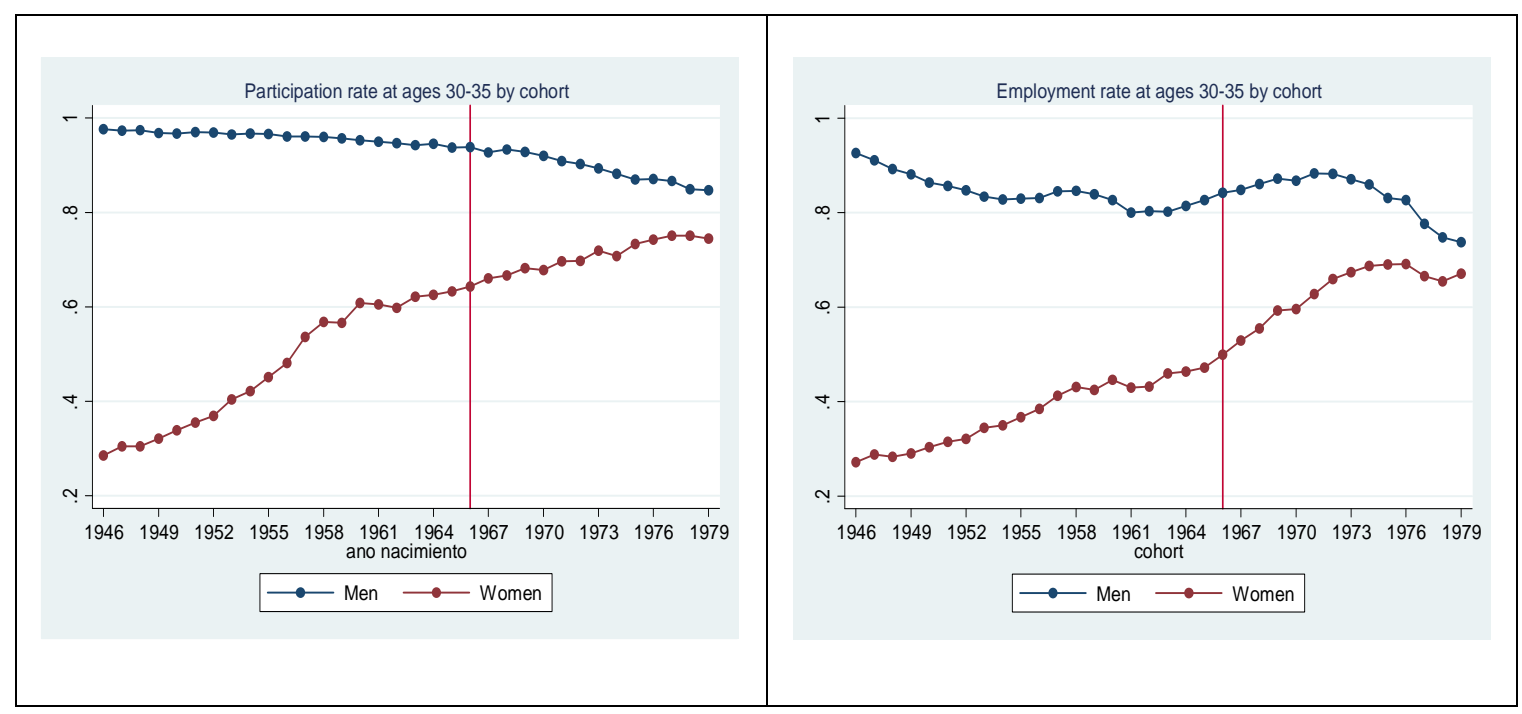

Source: Labour Force Survey (1976-2014).

Figure 2. Gender gap in life expectancy (women-men). 1991-2013.

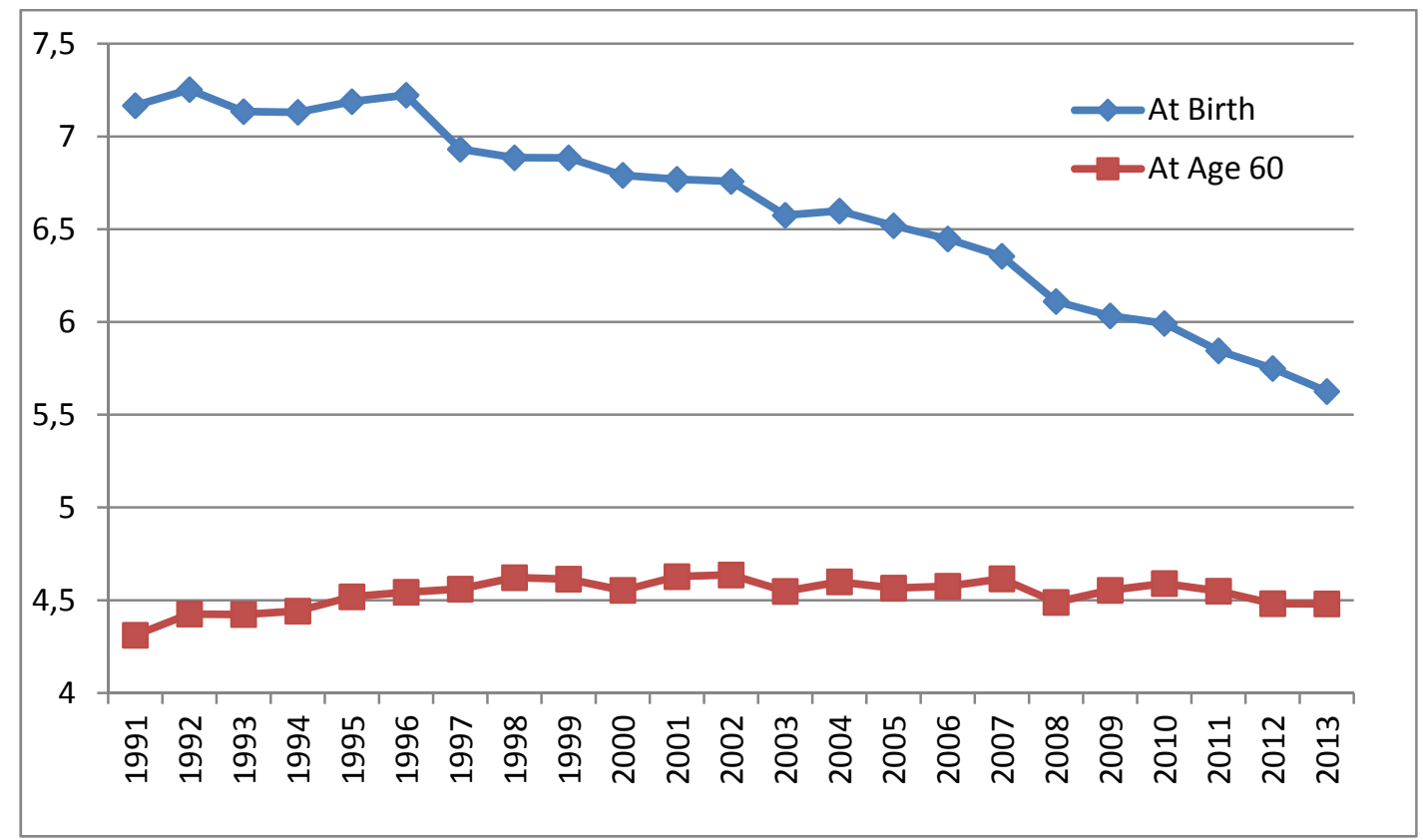

Source: National Institute of Statistics. 
Figure 3. Probability of being an early school leaver (ESL) and a high-school dropout.

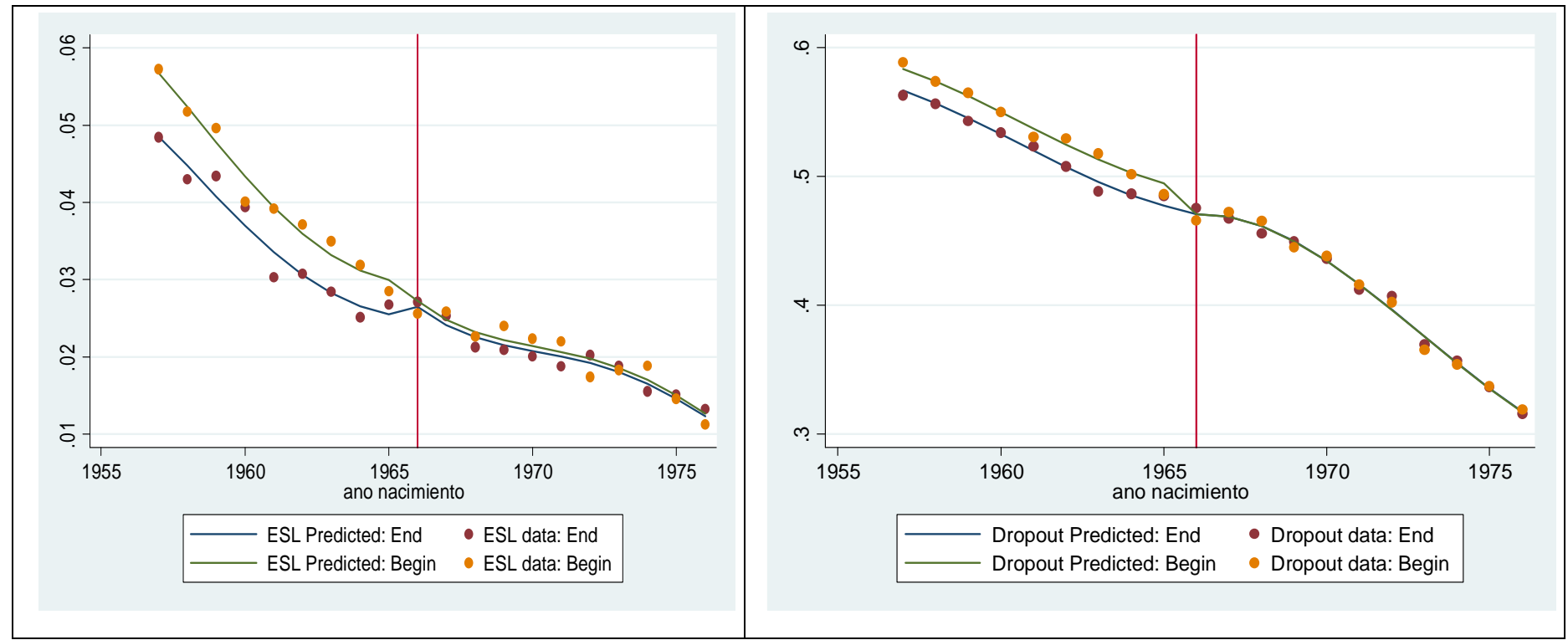

Note: The predictions are from a regression of the probability of being an ESL with quadratic trends and the dummies to identify the effect of the policy. Begin are individuals born in months 1 to 5 and end are those born in months 8 to 12 .

Source: Labour Force Survey (2000-2013).

Figure 4. Probability of being an ESL and a high-school dropout; Men.

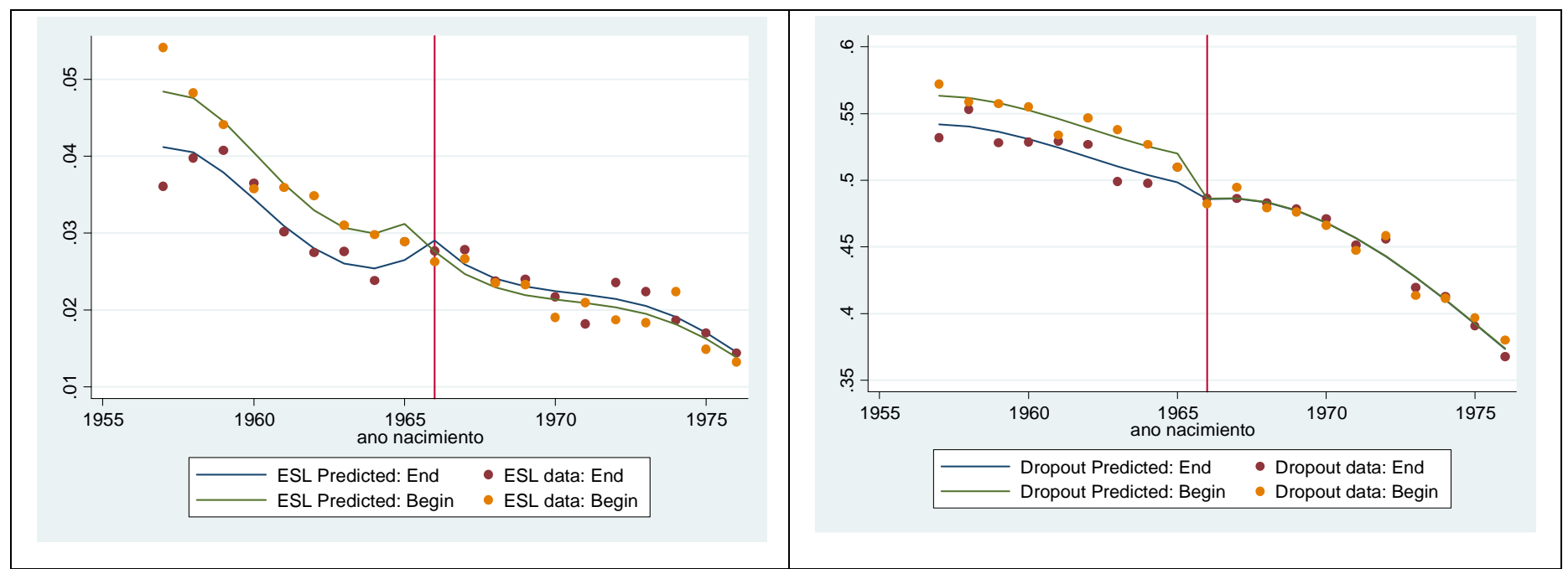

Note: The predictions are from a regression of the probability of being a dropout with quadratic trends and the dummies to identify the effect of the policy for a men only sample. Begin are individuals born in months 1 to 5 and end are those born in months 8 to 12 .

Source: Labour Force Survey (2000-2013). 
Figure 5. Probability of being an ESL and a high-school dropout; Women.

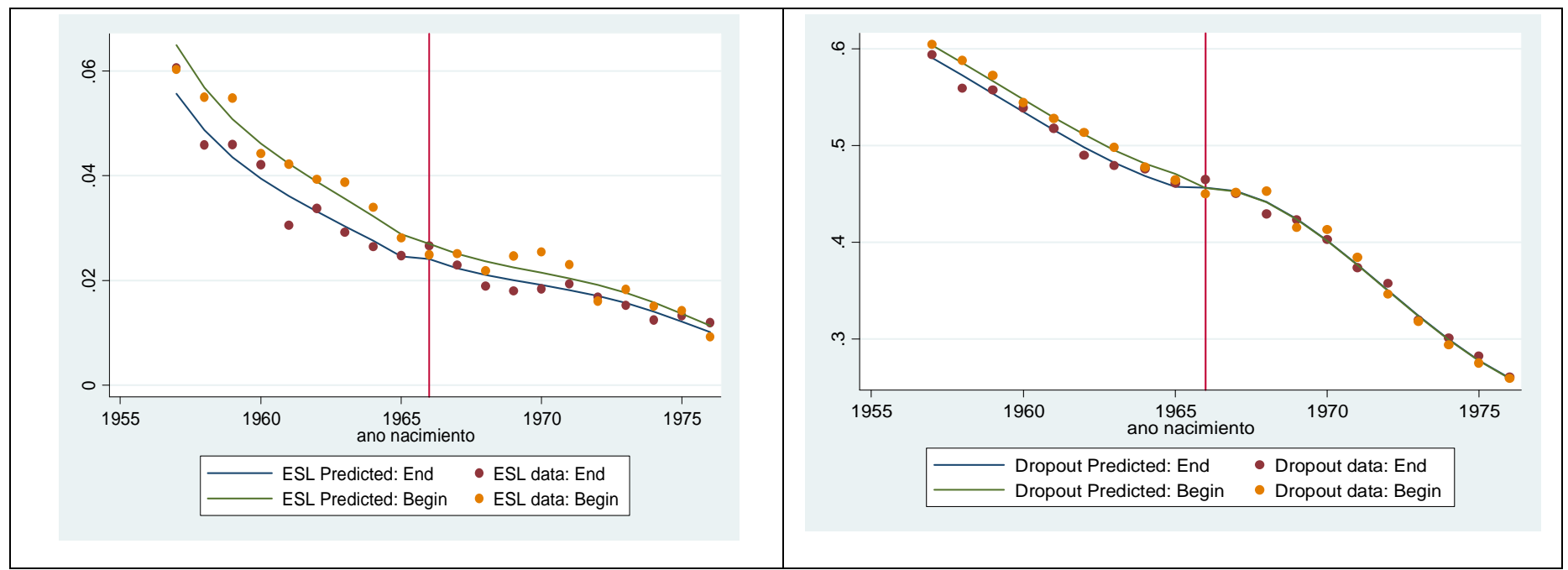

Note: The predictions are from a regression of the probability of being a dropout with quadratic trends and the dummies to identify the effect of the policy for a women only sample. Begin are individuals born in months 1 to 5 and end are those born in months 8 to 12 .

Source: Labour Force Survey (2000-2013). 
Figure 6. Percentage of men that die in each cohort, ages 16-25 and 26-40.

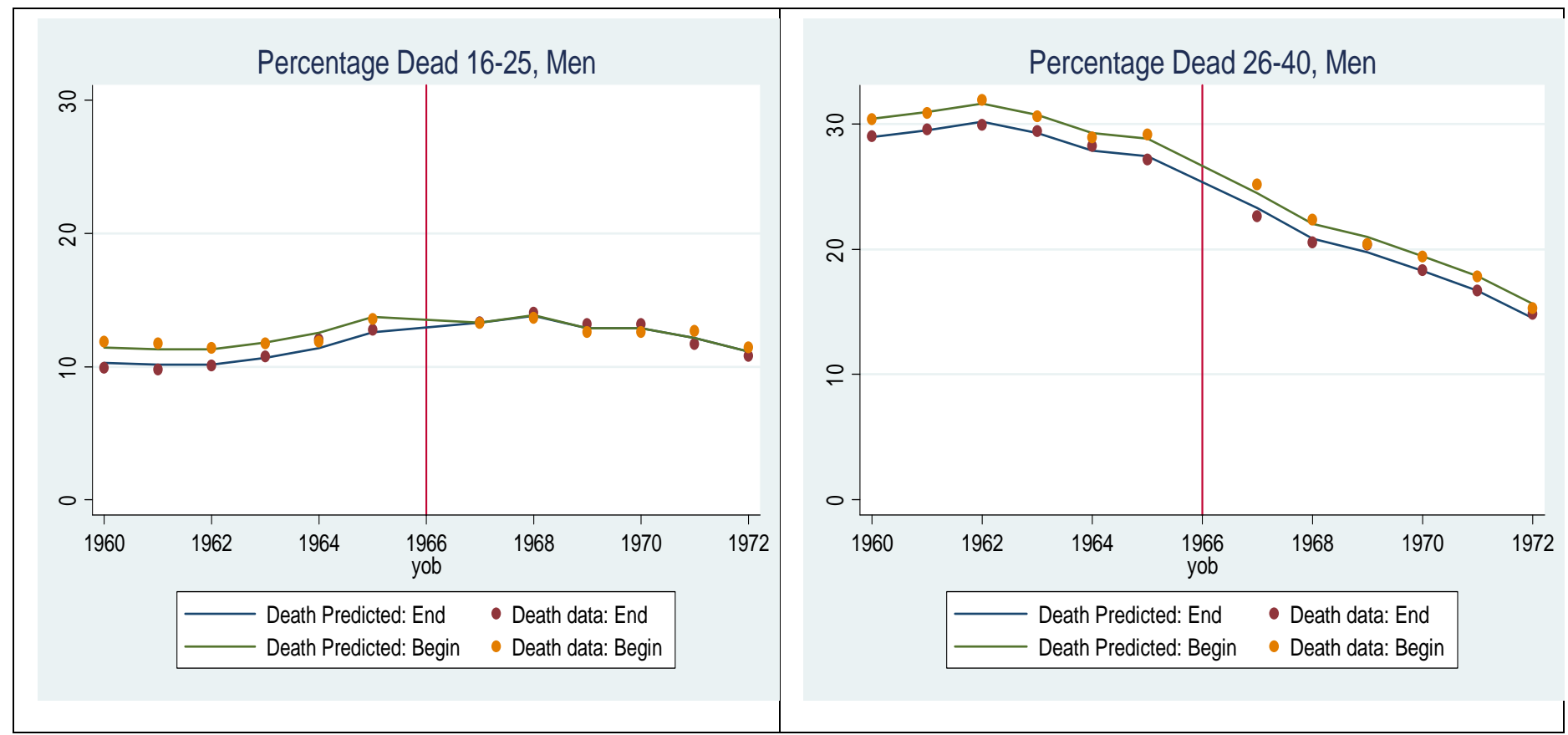

Note: The predictions are from a regression of the percentage of (treated and non-treated) men that dye in each cohort with cohort dummies and the dummies to identify the effect of the policy. Begin are individuals born in months 3, 4 and 5 and end are those born in months 8,9 and 10 .

Source: Mortality registries (1975-2012) and number of individuals born in each cohort from birth registries.

Figure 7. Percentage of women that die in each cohort, ages 16-25 and 26-40.

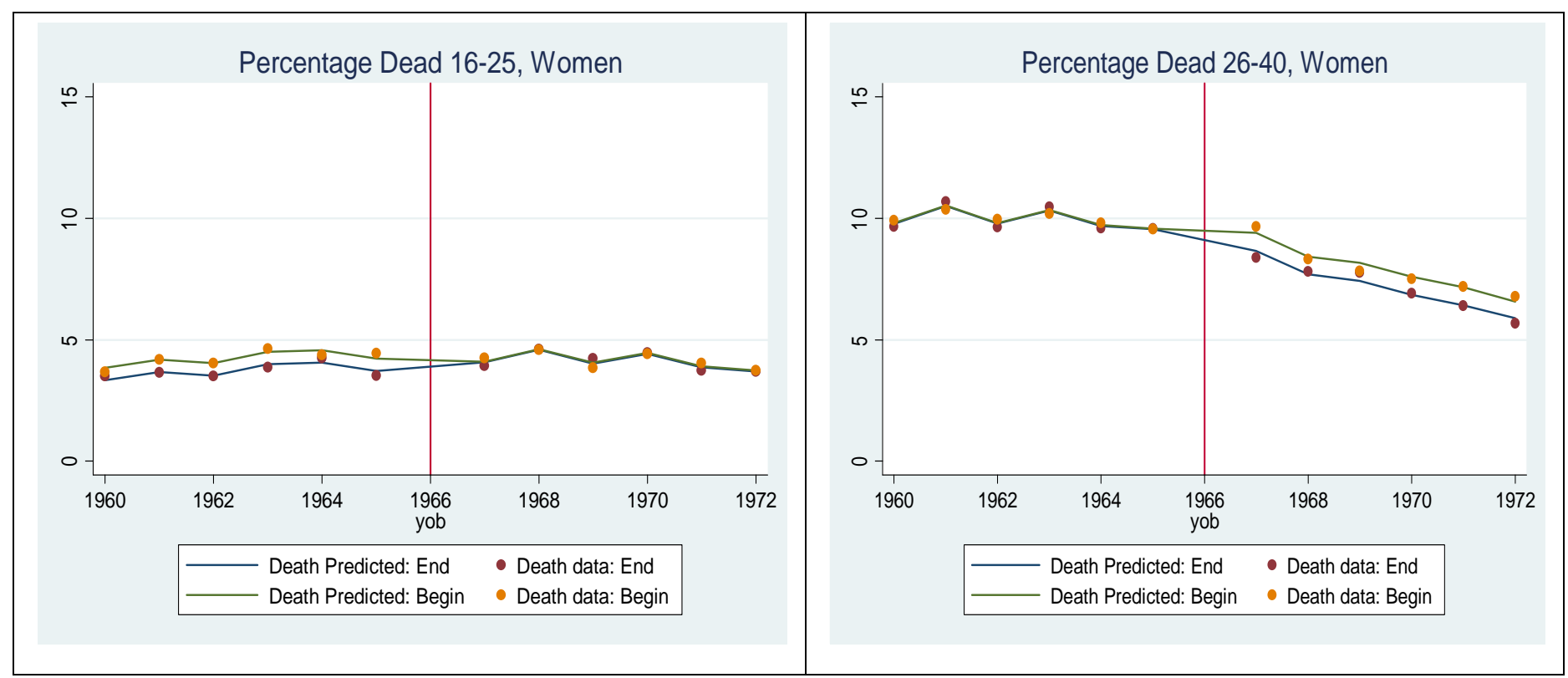

Note: The predictions are from a regression of the percentage of (treated and non-treated) women that dye in each cohort with cohort dummies and the dummies to identify the effect of the policy. Begin are individuals born in months 3, 4 and 5 and end are those born in months 8,9 and 10 .

Source: Mortality registries (1975-2012) and number of individuals born in each cohort from birth registries. 
Table 1. Early school leaver and high-school dropouts (LFS). Full sample.

\begin{tabular}{|c|c|c|c|c|}
\hline & \multicolumn{2}{|c|}{ Men } & \multicolumn{2}{|c|}{ Women } \\
\hline & ESL & DROPOUT & ESL & DROPOUT \\
\hline \multirow[t]{2}{*}{ treat } & $0.562 * * *$ & $1.957 * * *$ & $0.595 * * *$ & $1.134 * * *$ \\
\hline & $(0.158)$ & $(0.393)$ & $(0.155)$ & $(0.407)$ \\
\hline \multirow[t]{2}{*}{ treatpost } & $-0.642 * * *$ & $-1.826 * * *$ & $-0.368^{*}$ & $-0.987 *$ \\
\hline & $(0.194)$ & $(0.562)$ & $(0.190)$ & $(0.556)$ \\
\hline \multirow[t]{2}{*}{ trend } & 0.215 & $-0.855 * *$ & 0.259 & $-1.705 * * *$ \\
\hline & $(0.144)$ & $(0.428)$ & $(0.252)$ & $(0.389)$ \\
\hline \multirow[t]{2}{*}{ posttrend } & -0.088 & 0.564 & 0.015 & -0.064 \\
\hline & $(0.188)$ & $(0.515)$ & $(0.298)$ & $(0.507)$ \\
\hline \multirow[t]{2}{*}{ post } & $1.751 * * *$ & 0.495 & $2.379 * * *$ & $2.523 * *$ \\
\hline & $(0.495)$ & (1.253) & $(0.672)$ & $(1.231)$ \\
\hline \multirow[t]{2}{*}{ trend2 } & $0.032 * *$ & -0.023 & 0.044 & 0.018 \\
\hline & $(0.015)$ & $(0.039)$ & $(0.027)$ & $(0.037)$ \\
\hline \multirow[t]{2}{*}{ posttrend 2} & $-0.058 * * *$ & -0.068 & $-0.087 * *$ & -0.060 \\
\hline & $(0.020)$ & $(0.050)$ & $(0.034)$ & $(0.050)$ \\
\hline \multirow[t]{2}{*}{$\mathrm{Tp}$} & $-18.204 * * *$ & -1.602 & $-28.739 * * *$ & 10.797 \\
\hline & (3.105) & $(5.870)$ & $(4.304)$ & (7.118) \\
\hline \multirow[t]{2}{*}{ Constant } & $1.429 * * *$ & $35.031 * * *$ & $2.018 * * *$ & $37.753 * * *$ \\
\hline & $(0.352)$ & $(1.281)$ & $(0.559)$ & (1.447) \\
\hline Region FE & $\mathrm{X}$ & $\mathrm{X}$ & $\mathrm{X}$ & $\mathrm{X}$ \\
\hline Observations & 183,131 & 183,131 & 190,311 & 190,311 \\
\hline R-squared & 0.017 & 0.039 & 0.023 & 0.068 \\
\hline
\end{tabular}

Robust standard errors in parentheses

$* * * \mathrm{p}<0.01, * * \mathrm{p}<0.05, * \mathrm{p}<0.1$

Note: The dependent variable is the probability of being and ESL or a dropout multiplied by 100. Regressions include quadratic polynomial trends, the unemployment rate of the region and dummies for the 17 regions (autonomous communities in Spain). Treat are individuals born in months 1 to 5 and the control group are those born in months 8 to 12. Robust standard errors clustered at cohort and region level in parenthesis.

Source: Labour Force Survey (2000-2013). 
Table 2. Early school leaver and high-school dropouts (LFS). Reduced sample.

\begin{tabular}{ccccc}
\hline & \multicolumn{2}{c}{ Men } & \multicolumn{2}{c}{ Women } \\
\hline Treat & ESL & DROPOUT & ESL & DROPOUT \\
& $0.445^{* *}$ & $2.087^{* * *}$ & $0.340^{*}$ & $\left(0.085^{* *}\right.$ \\
treatpost & $(0.203)$ & $(0.518)$ & $-190)$ & $-1.202^{*}$ \\
& $-0.480^{*}$ & $-1.646^{* *}$ & $(0.189$ & $(0.698)$ \\
trend & $(0.248)$ & $(0.720)$ & $(0.226)$ & $-1.346^{* * *}$ \\
& 0.210 & -0.716 & $0.378^{*}$ & $(0.472)$ \\
posttrend & $(0.161)$ & $(0.486)$ & $(0.226)$ & -0.791 \\
& -0.226 & 0.680 & -0.048 & $(0.586)$ \\
post & $(0.207)$ & $(0.605)$ & $(0.297)$ & $3.168^{* *}$ \\
& $1.939 * * *$ & -0.654 & $1.807 * *$ & $(1.455)$ \\
trend2 & $(0.540)$ & $(1.486)$ & $(0.743)$ & 0.050 \\
& $0.030^{*}$ & -0.003 & $0.053 * *$ & $(0.046)$ \\
posttrend2 & $(0.016)$ & $(0.047)$ & $(0.024)$ & -0.059 \\
& $-0.044 * *$ & $-0.114 *$ & $-0.100^{* * *}$ & $(0.058)$ \\
tp & $(0.021)$ & $(0.059)$ & $(0.032)$ & 6.807 \\
Region FE & $-17.382^{* * *}$ & 2.580 & $-28.393 * * *$ & $(8.460)$ \\
R-squared & $(3.064)$ & $(7.732)$ & $(4.482)$ & $37.187 * * *$
\end{tabular}

Robust standard errors in parentheses

$* * * \mathrm{p}<0.01, * * \mathrm{p}<0.05, * \mathrm{p}<0.1$

Note: The dependent variable is the probability of being and ESL or a dropout multiplied by 100. Regressions include quadratic polynomial trends, the unemployment rate of the region and dummies for the 17 regions (autonomous communities in Spain). Treat are individuals born in months 3, 4, 5 and the control group are those born in months 8, 9, 10. Robust standard errors clustered at cohort and region level in parenthesis.

Source: Labour Force Survey (2000-2013). 
Table 3. Probability of having studied at the university level. Full and reduced sample.

\begin{tabular}{|c|c|c|c|c|}
\hline & \multicolumn{2}{|c|}{ Full Sample } & \multicolumn{2}{|c|}{ Reduced Sample } \\
\hline & Men & Women & Men & Women \\
\hline \multirow[t]{2}{*}{ treat } & -0.323 & -0.037 & $-0.685^{*}$ & -0.202 \\
\hline & $(0.333)$ & $(0.317)$ & $(0.369)$ & $(0.407)$ \\
\hline \multirow[t]{2}{*}{ treatpost } & $0.820 *$ & 0.297 & $1.142 * *$ & 0.510 \\
\hline & $(0.475)$ & $(0.449)$ & $(0.542)$ & $(0.568)$ \\
\hline \multirow[t]{2}{*}{ trend } & 0.419 & $1.017 * * *$ & 0.334 & $0.683^{*}$ \\
\hline & $(0.274)$ & $(0.332)$ & $(0.285)$ & $(0.413)$ \\
\hline \multirow[t]{2}{*}{ posttrend } & $0.771^{*}$ & $1.100 * *$ & $0.865^{*}$ & $1.272 * *$ \\
\hline & $(0.421)$ & $(0.523)$ & $(0.489)$ & $(0.611)$ \\
\hline \multirow[t]{2}{*}{ post } & 0.083 & -0.186 & 0.694 & -0.530 \\
\hline & $(0.850)$ & $(0.954)$ & $(0.945)$ & $(1.170)$ \\
\hline \multirow[t]{2}{*}{ trend2 } & $0.046^{*}$ & 0.028 & 0.036 & -0.002 \\
\hline & $(0.027)$ & $(0.031)$ & $(0.028)$ & (0.039) \\
\hline \multirow[t]{2}{*}{ posttrend2 } & $-0.144 * * *$ & $-0.164 * *$ & $-0.132 * *$ & -0.115 \\
\hline & $(0.051)$ & (0.065) & $(0.060)$ & $(0.074)$ \\
\hline \multirow[t]{2}{*}{ tp } & $-15.544 * * *$ & $-26.866 * * *$ & $-20.663 * * *$ & $-19.861 * * *$ \\
\hline & $(5.232)$ & $(6.880)$ & (6.151) & $(7.467)$ \\
\hline \multirow[t]{2}{*}{ Constant } & $19.874 * * *$ & $26.890 * * *$ & $19.016 * * *$ & $30.223 * * *$ \\
\hline & (0.994) & $(1.213)$ & $(1.115)$ & (1.739) \\
\hline Observations & 180,449 & 188,542 & 116,759 & 121,896 \\
\hline R-squared & 0.013 & 0.022 & 0.013 & 0.021 \\
\hline
\end{tabular}

Robust standard errors in parentheses

$* * * p<0.01, * * p<0.05, * p<0.1$

Note: The dependent variable is the probability of having studied at the university level (at least 3 courses passed of any university degree) multiplied by 100 . Regressions include quadratic polynomial trends, the unemployment rate of the region and dummies for the 17 regions (autonomous communities in Spain). Treat are individuals born in months 3, 4, 5 and the control group are those born in months $8,9,10$. Robust standard errors clustered at cohort and region level in parenthesis.

Source: Labour Force Survey (2000-2013). 
Table 4. Mortality at ages $15-40$ as a percentage of individuals in the cohort.

\begin{tabular}{lcccc}
\hline & \multicolumn{2}{c}{ Full Sample } & \multicolumn{2}{c}{ Reduced Sample } \\
\hline treat & Men & Women & Men & Women \\
& $0.101^{* * *}$ & $0.017^{* * *}$ & $0.092^{* * *}$ & $(0.005)$ \\
treatpost & $(0.019)$ & $(0.005)$ & $(0.016)$ & 0.007 \\
& -0.030 & 0.018 & $-0.052^{* *}$ & $(0.011)$ \\
postref & $(0.022)$ & $(0.011)$ & $(0.022)$ & $-0.271^{* * *}$ \\
& $-0.754^{* * *}$ & $-0.266^{* * *}$ & $-0.733^{* * *}$ & $(0.010)$ \\
Constant & $(0.028)$ & $(0.009)$ & $(0.027)$ & $0.699^{* * *}$ \\
& $1.650^{* * *}$ & $0.690^{* * *}$ & $1.623^{* * *}$ & $(0.049)$ \\
Observations & $(0.255)$ & $(0.060)$ & $(0.228)$ & 646 \\
R-squared & & & 646 & 0.809 \\
\hline
\end{tabular}

Robust standard errors in parentheses

$* * * \mathrm{p}<0.01, * * \mathrm{p}<0.05, * \mathrm{p}<0.1$

Note The dependent variable is the number of individuals that die in each cohort and treatment status divided by the number of individuals born in each cohort and treatment status multiplied by 1000 . Regressions include cohort and calendar time dummies. Treated are individuals born in either in all months ( 1 to 5) or on months 3, 4 and 5 and control are those born either in all months ( 8 to 12 ) or in months 8, 9 and 10. Cohorts included; 1960-1972 (ages 15-40 in 1975-2012). Robust standard errors clustered by cohort.

Source: Mortality registries (1975-2012) and number of individuals born in each cohort from birth registries.

Table 5. Mortality by age group. Reduced sample.

\begin{tabular}{lcccc}
\hline & \multicolumn{2}{c}{ Ages 15-25 } & \multicolumn{2}{c}{ Ages 26-40 } \\
\hline treat & Men & Women & Men & 0.001 \\
& $0.090^{* * *}$ & $0.042^{* * *}$ & $0.079 * * *$ & $(0.007)$ \\
treatpost & $(0.026)$ & $(0.011)$ & $(0.012)$ & $0.042^{* * *}$ \\
& $-0.090^{* *}$ & $-0.039 * *$ & -0.012 & $(0.013)$ \\
postref & $(0.034)$ & $(0.014)$ & $(0.024)$ & $-0.266^{* * *}$ \\
& $-0.429 * * *$ & $-0.099^{* * *}$ & $-0.535^{* * *}$ & $(0.010)$ \\
Constant & $(0.074)$ & $(0.021)$ & $(0.026)$ & $0.680^{* * *}$ \\
& -0.016 & $0.125^{* * *}$ & $1.389 * * *$ & $(0.045)$ \\
Observations & $(0.020)$ & $(0.012)$ & $(0.212)$ & 406 \\
R-squared & & & 406 & 0.538 \\
\hline
\end{tabular}

Robust standard errors in parentheses

$* * * \mathrm{p}<0.01, * * \mathrm{p}<0.05, * \mathrm{p}<0.1$

Note: The dependent variable is the number of individuals that die in each cohort, age group and treatment status divided by the number of individuals born in each cohort and treatment status multiplied by 1000. Regressions include cohort and calendar time dummies. Treated are individuals born in months 3,4 and 5 and control are those born in months 8, 9 and 10. Cohorts included; 1960-1972 (ages 15-40 in 1975-2012). Robust standard errors clustered by cohort.

Source: Mortality registries (1975-2012) and number of individuals born in each cohort from birth registries. 
Table 6. Employment Outcomes (LFS). Reduced Sample.

\begin{tabular}{|c|c|c|c|c|c|c|c|c|}
\hline & \multicolumn{4}{|c|}{ Men } & \multicolumn{4}{|c|}{ Women } \\
\hline & Employ & Construct & Low Skill & Inactive & Employ & Construct & Low Skill & Inactive \\
\hline \multirow[t]{2}{*}{ treat } & -0.390 & $0.713 * *$ & 0.694 & -0.035 & $-1.541 * * *$ & 0.152 & 0.581 & $1.397 * *$ \\
\hline & $(0.261)$ & $(0.261)$ & $(0.652)$ & $(0.334)$ & (0.439) & $(0.127)$ & $(0.507)$ & $(0.531)$ \\
\hline \multirow[t]{2}{*}{ treatpost } & $0.595^{*}$ & $-0.810 * *$ & $-1.911^{* *}$ & -0.057 & $1.347^{*}$ & 0.059 & -0.144 & $-1.319 *$ \\
\hline & $(0.317)$ & $(0.349)$ & (0.899) & $(0.369)$ & (0.689) & $(0.190)$ & $(0.686)$ & $(0.638)$ \\
\hline \multirow[t]{2}{*}{ postref } & $-0.320 *$ & $1.839 * * *$ & $5.635^{* * *}$ & $-4.008 * * *$ & $10.553 * * *$ & $0.895^{* * *}$ & $-9.381 * * *$ & $-15.410 * * *$ \\
\hline & $(0.166)$ & $(0.182)$ & $(0.460)$ & $(0.185)$ & (0.331) & $(0.097)$ & $(0.353)$ & $(0.301)$ \\
\hline \multirow[t]{2}{*}{ Constant } & $88.517 * * *$ & $17.251 * * *$ & $45.309 * * *$ & $9.441^{* * *}$ & $56.411 * * *$ & $1.744^{* * *}$ & $24.675^{* * *}$ & $39.652 * * *$ \\
\hline & $(0.603)$ & $(1.045)$ & $(1.427)$ & $(0.500)$ & $(1.331)$ & $(0.500)$ & $(1.538)$ & (1.338) \\
\hline Obs & 2,242 & 2,242 & 2,242 & 2,242 & 2,242 & 2,242 & 2,242 & 2,242 \\
\hline R-squared & 0.489 & 0.707 & 0.275 & 0.155 & 0.325 & 0.148 & 0.226 & 0.500 \\
\hline
\end{tabular}

Robust standard errors in parentheses

$* * * \mathrm{p}<0.01, * * \mathrm{p}<0.05, * \mathrm{p}<0.1$

Note: The dependent variable is the probability of being employed, working in the construction sector, working in a low-skill job or being inactive multiplied by 100. Regressions include cohort and calendar time dummies (trimesters). Treated are individuals born in either in all months ( 1 to 5) or on months 3, 4 and 5 and control are those born either in all months (8 to 12) or in months 8, 9 and 10. Cohorts included; 1956-1976. Robust standard errors clustered by cohort.

Source: Labour Force Survey (2000-2013).

Table 7. Employment Outcomes Men (MCVL). Reduced Sample.

\begin{tabular}{lccccc}
\hline & Employ & Log(wages) & Temporary & LM Experience & Date LM Entry \\
\hline \multirow{2}{*}{ treat } & & & & & $-139.563^{* * *}$ \\
& $-0.623^{* *}$ & $-0.008^{* *}$ & $0.383^{* *}$ & -16.355 & $(17.477)$ \\
treatpost & $(0.255)$ & $(0.003)$ & $(0.174)$ & $(133.658)$ & $46.168^{* *}$ \\
& 0.439 & 0.007 & $-0.553^{* *}$ & 35.559 & $(20.804)$ \\
postref & $(0.340)$ & $(0.005)$ & $(0.247)$ & $(146.602)$ & $248.247^{* * *}$ \\
& 0.997 & $-0.027^{* * *}$ & $4.796^{* * *}$ & $-5,638^{* * *}$ & $(63.087)$ \\
Constant & $(0.709)$ & $(0.008)$ & $(0.485)$ & $(252.786)$ & $7,576^{* * *}$ \\
& $74.559 * * *$ & $11.973^{* * *}$ & $4.457^{* * *}$ & $13,948 * * *$ & $(68.097)$ \\
& $(0.729)$ & $(0.011)$ & $(0.588)$ & $(330.185)$ & 19,040 \\
Observations & 19,040 & 19,040 & 19,040 & 19,040 & 0.754 \\
R-squared & 0.839 & 0.891 & 0.696 & 0.900 & \\
\hline
\end{tabular}

Robust standard errors in parentheses

$* * * p<0.01, * * p<0.05, * p<0.1$

Note: The dependent variable is the probability of being employed or having a temporary contract (both multiplied by 100), the logarithm of wages, accumulated LM experience since the first labor market experience and date of entry in the labor market for the first time. Regressions include cohort, calendar time and region fixed effects. Treated are individuals born in months 3,4 and 5 and control are those born in months 8, 9 and 10. Cohorts included; 1956-1976. Robust standard errors clustered by cohort.

Source: Social Security administrative database (MCVL). 
Table 8. Employment Outcomes Women (MCVL). Reduced Sample.

\begin{tabular}{|c|c|c|c|c|c|}
\hline & Employ & Log(wages) & Temporary & LM Experience & Date LM Entry \\
\hline \multirow[t]{2}{*}{ treat } & -0.512 & -0.002 & 0.081 & 201.305 & $-142.963 * * *$ \\
\hline & $(0.324)$ & $(0.006)$ & $(0.190)$ & (129.813) & $(28.218)$ \\
\hline \multirow[t]{2}{*}{ treatpost } & 0.153 & 0.003 & 0.064 & $-330.449 * *$ & $79.727^{* *}$ \\
\hline & $(0.407)$ & $(0.008)$ & $(0.260)$ & $(140.786)$ & (31.195) \\
\hline \multirow[t]{2}{*}{ postref } & $2.317^{* *}$ & -0.031 & $4.438 * * *$ & $-3,668 * * *$ & $-402.363^{*}$ \\
\hline & (0.899) & $(0.024)$ & $(0.533)$ & (478.201) & (210.007) \\
\hline \multirow[t]{2}{*}{ Constant } & $71.775 * * *$ & $11.784 * * *$ & $5.989 * * *$ & $10,221 * * *$ & $8,374 * * *$ \\
\hline & $(1.203)$ & $(0.030)$ & $(1.014)$ & (549.290) & (218.598) \\
\hline Observations & 19,040 & 19,040 & 19,040 & 19,040 & 19,040 \\
\hline R-squared & 0.698 & 0.782 & 0.514 & 0.801 & 0.723 \\
\hline
\end{tabular}

Robust standard errors in parentheses

$* * * p<0.01, * * p<0.05, * p<0.1$

Note: The dependent variable is the probability of being employed or having a temporary contract (both multiplied by 100), the logarithm of wages, accumulated LM experience since the first labor market experience and date of entry in the labor market for the first time. Regressions include cohort, calendar time and region fixed effects. Treated are individuals born in months 3,4 and 5 and control are those born in months 8, 9 and 10. Cohorts included; 1956-1976. Robust standard errors clustered by cohort and region.

Source: Social Security administrative database (MCVL).

Table 9. Working Accidents by Type of Accident. Reduced Sample.

\begin{tabular}{|c|c|c|c|c|c|c|c|c|}
\hline & \multicolumn{4}{|c|}{ Ages 28-41 } & \multicolumn{4}{|c|}{ Ages 28-35 } \\
\hline & \multicolumn{2}{|c|}{ Men } & \multicolumn{2}{|c|}{ Women } & \multicolumn{2}{|c|}{ Men } & \multicolumn{2}{|c|}{ Women } \\
\hline & Dead & Total & Dead & Total & Dead & Total & Dead & Total \\
\hline \multirow[t]{2}{*}{ Treat } & 0.008 & 0.554 & 0.000 & 0.093 & 0.014 & $0.878^{*}$ & 0.000 & 0.027 \\
\hline & $(0.006)$ & $(0.315)$ & $(0.001)$ & $(0.066)$ & $(0.008)$ & $(0.428)$ & $(0.001)$ & $(0.111)$ \\
\hline \multirow[t]{2}{*}{ treatpost } & -0.005 & $-0.896 * *$ & 0.002 & $-0.399 * *$ & -0.015 & $-1.176 * *$ & 0.002 & $-0.395^{*}$ \\
\hline & $(0.007)$ & $(0.368)$ & $(0.002)$ & $(0.164)$ & (0.009) & $(0.509)$ & $(0.003)$ & $(0.216)$ \\
\hline \multirow[t]{2}{*}{ Postref } & -0.031 & $5.132 * * *$ & $0.011^{* * *}$ & $-0.825^{* *}$ & -0.042 & $6.898 * * *$ & $0.016^{*}$ & $-1.464 * * *$ \\
\hline & $(0.022)$ & (0.997) & $(0.003)$ & (0.329) & $(0.024)$ & $(1.255)$ & $(0.007)$ & $(0.420)$ \\
\hline \multirow[t]{2}{*}{ Constant } & $0.046 *$ & $12.650 * * *$ & $-0.010 * * *$ & $10.071 * * *$ & $0.098 * * *$ & $53.957 * * *$ & 0.000 & $7.753^{* * *}$ \\
\hline & $(0.022)$ & (0.769) & $(0.002)$ & $(0.306)$ & $(0.022)$ & $(1.131)$ & $(0.004)$ & $(0.349)$ \\
\hline Obs & 336 & 336 & 336 & 336 & 192 & 192 & 192 & 192 \\
\hline R-squared & 0.357 & 0.985 & 0.094 & 0.980 & 0.262 & 0.989 & 0.112 & 0.992 \\
\hline
\end{tabular}

Robust standard errors in parentheses

$* * * \mathrm{p}<0.01, * * \mathrm{p}<0.05, * \mathrm{p}<0.1$

Note: The dependent variable is the number of individuals that suffer from a working accident for each cohort, age group and treatment status divided by the number of individuals born in each cohort and treatment status multiplied by 1000 . Regressions include calendar time dummies and third-order polynomial trends. Treated are individuals born in months 3, 4 and 5 and control are those born in months 8, 9 and 10. Cohorts included; 1960-1972 (ages 28-41 in 1988-2013). Robust standard errors clustered by cohort.

Source: Working accidents registries (1988-2013) and number of individuals born in each cohort from birth registries. 
Table 10. New permanent disability beneficiaries (MCVL)

\begin{tabular}{lcccc}
\hline & \multicolumn{2}{c}{ Full Sample } & \multicolumn{2}{c}{ Reduced Sample } \\
\hline treat & Men & Women & Men & Women \\
& $0.006^{* *}$ & $-0.003^{* *}$ & 0.004 & -0.003 \\
treatpost & $(0.003)$ & $(0.001)$ & $(0.004)$ & $(0.002)$ \\
& -0.006 & $0.004^{*}$ & -0.004 & 0.002 \\
postref & $(0.003)$ & $(0.002)$ & $(0.006)$ & $(0.003)$ \\
& -0.006 & 0.003 & -0.014 & -0.005 \\
Constant & $(0.010)$ & $(0.008)$ & $(0.009)$ & $(0.006)$ \\
& 0.015 & -0.000 & $0.030^{* * *}$ & -0.006 \\
& $(0.009)$ & $(0.007)$ & $(0.009)$ & $(0.007)$ \\
Observations & & & & \\
R-squared & 508 & 442 & 489 & 410 \\
\hline
\end{tabular}

Robust standard errors in parentheses

$* * * \mathrm{p}<0.01, * * \mathrm{p}<0.05, * \mathrm{p}<0.1$

Note: The regressions include third-order polynomial trends and time fixed effects. Treat are individuals born in months 1 to 5 (3, $4,5)$ and the control group are those born in months 8 to $12(8,9,10)$. The dependent variable is the number of individuals entering the permanent disability benefits system for each cohort and treatment status divided by the number of individuals born in each cohort and treatment status multiplied by 1000. Cohorts included; 1960-1972. Robust standard errors clustered by cohort.

Source: Administrative Social Security Records (MCVL) (1990-2011) and number of individuals born in each cohort from birth registries.

Table 11. Probability of having bad healthy habits Men (NHS). Reduced Sample.

\begin{tabular}{|c|c|c|c|c|c|c|}
\hline & $\begin{array}{c}\text { High Blood } \\
\text { Pressure }\end{array}$ & Bronchitis & Diabetes & Smoke/day & Smoke/regularly & Beer/day \\
\hline \multirow[t]{2}{*}{ treat } & 0.027 & -0.002 & $0.011^{*}$ & 0.004 & 0.001 & -0.015 \\
\hline & $(0.024)$ & $(0.006)$ & $(0.006)$ & $(0.030)$ & $(0.031)$ & $(0.018)$ \\
\hline \multirow[t]{2}{*}{ treatpost } & -0.005 & -0.003 & -0.014 & -0.005 & 0.004 & 0.007 \\
\hline & $(0.029)$ & (0.009) & $(0.008)$ & $(0.041)$ & $(0.043)$ & $(0.024)$ \\
\hline \multirow[t]{2}{*}{ post } & $-0.162 * * *$ & $-0.023 * * *$ & $-0.010 * *$ & $-0.051 * *$ & -0.028 & $-0.154 * * *$ \\
\hline & $(0.015)$ & $(0.005)$ & $(0.004)$ & $(0.022)$ & $(0.023)$ & $(0.012)$ \\
\hline \multirow[t]{2}{*}{ Constant } & $0.202 * * *$ & $0.046 * * *$ & $0.021 * * *$ & $0.439 * * *$ & $0.495 * * *$ & $0.260 * * *$ \\
\hline & $(0.013)$ & $(0.003)$ & $(0.003)$ & $(0.016)$ & $(0.016)$ & $(0.009)$ \\
\hline Observations & 2,113 & 2,113 & 2,113 & 2,113 & 2,113 & 2,113 \\
\hline R-squared & 0.035 & 0.011 & 0.016 & 0.004 & 0.004 & 0.015 \\
\hline
\end{tabular}

Robust standard errors in parentheses

$* * * p<0.01, * * p<0.05, * p<0.1$

Note: The dependent variable is the probability of having high blood pressure, the probability of suffering from bronquitis, diabetes, of smoking every day or regularly and drinking beer every day. Regressions include cohort fixed effects. Treated are individuals born in months 3, 4 and 5 and control are those born in months 8, 9 and 10. Cohorts included; 1956-1976. Robust standard errors clustered by cohort.

Source: National Health Survey 2006. 
Table 12. Probability of having bad healthy habits Women (NHS). Reduced Sample.

\begin{tabular}{|c|c|c|c|c|c|c|}
\hline & $\begin{array}{l}\text { High Blood } \\
\text { Pressure }\end{array}$ & Bronchitis & Diabetes & Smoke/day & Smoke/regularly & Beer/day \\
\hline \multirow[t]{2}{*}{ treat } & $-0.028 *$ & $-0.028 * *$ & -0.007 & -0.031 & -0.037 & -0.008 \\
\hline & $(0.013)$ & $(0.010)$ & $(0.010)$ & $(0.021)$ & $(0.024)$ & $(0.006)$ \\
\hline \multirow[t]{2}{*}{ treatpost } & $0.038 *$ & $0.045^{* * *}$ & 0.014 & 0.051 & $0.059 *$ & $0.028 * *$ \\
\hline & (0.019) & $(0.012)$ & $(0.012)$ & $(0.029)$ & $(0.034)$ & $(0.010)$ \\
\hline \multirow[t]{2}{*}{ post } & $-0.194 * * *$ & $-0.036 * * *$ & -0.006 & $-0.115^{* * *}$ & $-0.091 * * *$ & $-0.041 * * *$ \\
\hline & $(0.010)$ & $(0.006)$ & $(0.006)$ & $(0.015)$ & $(0.017)$ & $(0.005)$ \\
\hline \multirow[t]{2}{*}{ Constant } & $0.237 * * *$ & $0.062 * * *$ & $0.037 * * *$ & $0.334 * * *$ & $0.357 * * *$ & $0.045^{* * *}$ \\
\hline & $(0.007)$ & $(0.005)$ & $(0.005)$ & $(0.011)$ & $(0.012)$ & $(0.003)$ \\
\hline Observations & 3,046 & 3,046 & 3,046 & 3,046 & 3,046 & 3,046 \\
\hline R-squared & 0.025 & 0.014 & 0.005 & 0.006 & 0.006 & 0.006 \\
\hline
\end{tabular}

Robust standard errors in parentheses

$* * * p<0.01, * * p<0.05, * p<0.1$

Note: The dependent variable is the probability of having high blood pressure, the probability of suffering from bronquitis, diabetes, of smoking every day or regularly and drinking beer every day. Regressions include cohort fixed effects. Treated are individuals born in months 3, 4 and 5 and control are those born in months 8, 9 and 10. Cohorts included; 1956-1976. Robust standard errors clustered by cohort.

Source: National Health Survey 2006.

Table 13. Hospitalizations by type of diseases. Short-term; ages 17-25. Reduced Sample.

\begin{tabular}{|c|c|c|c|c|c|c|c|c|}
\hline & \multicolumn{4}{|c|}{ MEN } & \multicolumn{4}{|c|}{ WOMEN } \\
\hline & Subs.Abuse & Respiratory & Mental & Injuries & Subs.Abuse & Respiratory & Mental & Injuries \\
\hline \multirow[t]{2}{*}{ treat } & $0.020 * *$ & 0.045 & $0.096 * * *$ & $0.097 * * *$ & $0.012 * *$ & 0.003 & $0.048 * *$ & 0.045 \\
\hline & $(0.007)$ & $(0.025)$ & $(0.006)$ & $(0.023)$ & $(0.004)$ & $(0.004)$ & $(0.016)$ & $(0.034)$ \\
\hline \multirow[t]{2}{*}{ treatpost } & 0.000 & -0.035 & -0.009 & 0.071 & -0.010 & $-0.031 * *$ & -0.001 & -0.032 \\
\hline & $(0.040)$ & $(0.046)$ & $(0.067)$ & $(0.084)$ & (0.007) & (0.009) & $(0.033)$ & $(0.037)$ \\
\hline \multirow[t]{2}{*}{ Constant } & $0.487^{* * *}$ & $0.844 * * *$ & $1.458 * * *$ & $1.899 * * *$ & $0.138 * * *$ & $0.450 * * *$ & $0.539 * * *$ & $1.237^{* * *}$ \\
\hline & $(0.018)$ & $(0.063)$ & $(0.067)$ & $(0.142)$ & $(0.007)$ & $(0.015)$ & $(0.011)$ & $(0.027)$ \\
\hline Observations & 108 & 108 & 108 & 108 & 108 & 108 & 108 & 108 \\
\hline R-squared & 0.763 & 0.515 & 0.802 & 0.755 & 0.790 & 0.763 & 0.835 & 0.928 \\
\hline
\end{tabular}

Robust standard errors in parentheses

$* * * \mathrm{p}<0.01, * * \mathrm{p}<0.05, * \mathrm{p}<0.1$

Note: The regressions include cohort and time fixed effects. Treat are individuals born in months 3, 4, 5 and the control group are those born in months $8,9,10$. The dependent variable is the number of individuals being hospitalized due to each type of diseases for each cohort and treatment status divided by the number of individuals born in each cohort and treatment status multiplied by 1000. Cohorts included; 1963-1969. Ages included from 17 to 25 years old. Robust standard errors clustered by cohort.

Source: Register data on hospitalizations (1980-2013) and number of individuals born in each cohort from birth registries. 
Table 14. Hospitalizations by type of diseases. Long-term; ages 26-44. Reduced Sample.

\begin{tabular}{|c|c|c|c|c|c|c|c|c|}
\hline & \multicolumn{4}{|c|}{ MEN } & \multicolumn{4}{|c|}{ WOMEN } \\
\hline & Subs.Abuse & Respiratory & Mental & Injuries & Subs.Abuse & Respiratory & Mental & Injuries \\
\hline \multirow[t]{2}{*}{ treat } & 0.028 & $-0.043 * *$ & 0.067 & $0.109 * *$ & -0.003 & $-0.094 * *$ & 0.113 & 0.021 \\
\hline & $(0.027)$ & $(0.016)$ & $(0.068)$ & $(0.042)$ & $(0.008)$ & $(0.036)$ & $(0.068)$ & (0.039) \\
\hline \multirow[t]{2}{*}{ treatpost } & -0.057 & 0.067 & 0.054 & -0.144 & -0.040 & $0.134 * *$ & -0.154 & $-0.141^{*}$ \\
\hline & $(0.060)$ & $(0.065)$ & $(0.076)$ & $(0.075)$ & $(0.025)$ & $(0.048)$ & (0.119) & $(0.067)$ \\
\hline \multirow[t]{2}{*}{ Constant } & $0.312 * * *$ & $0.181 * * *$ & $0.991 * * *$ & $2.063 * * *$ & $0.114^{* * *}$ & $0.229 * * *$ & $0.346^{* * *}$ & $0.822^{* * *}$ \\
\hline & $(0.030)$ & $(0.040)$ & $(0.041)$ & $(0.032)$ & $(0.009)$ & $(0.018)$ & $(0.057)$ & $(0.017)$ \\
\hline Observations & 216 & 216 & 216 & 216 & 216 & 216 & 216 & 216 \\
\hline R-squared & 0.912 & 0.980 & 0.963 & 0.989 & 0.815 & 0.975 & 0.965 & 0.967 \\
\hline
\end{tabular}

Robust standard errors in parentheses

$* * * \mathrm{p}<0.01, * * \mathrm{p}<0.05, * \mathrm{p}<0.1$

Note: The regressions include cohort and time fixed effects. Treat are individuals born in months 3, 4, 5 and the control group are those born in months $8,9,10$. The dependent variable is the number of individuals being hospitalized due to each type of diseases for each cohort and treatment status divided by the number of individuals born in each cohort and treatment status multiplied by 1000. Cohorts included; 1963-1969. Ages included from 26 to 44 years old. Robust standard errors clustered by cohort.

Source: Register data on hospitalizations (1980-2013) and number of individuals born in each cohort from birth registries.

Table 15. Probability of having bad healthy habits. Full Sample.

\begin{tabular}{ccc}
\hline & \multicolumn{2}{c}{ Drugs (Injectable) } \\
\hline treat & $0.012^{*}$ & Women \\
& $(0.007)$ & $-0.009^{* *}$ \\
treatpost & $-0.029^{* *}$ & $(0.004)$ \\
& $(0.011)$ & -0.001 \\
post & $0.048^{* * *}$ & $(0.012)$ \\
& $(0.006)$ & $0.041^{* * *}$ \\
Constant & $-0.007^{*}$ & $(0.006)$ \\
& $(0.004)$ & $0.004^{* *}$ \\
Observations & 1,640 & $(0.002)$ \\
R-squared & 0.014 & 1,904 \\
\hline
\end{tabular}

Robust standard errors in parentheses

$* * * p<0.01, * * p<0.05, * p<0.1$

Note: The dependent variable is the probability of having tried injectable drugs. Regressions include cohort dummies. Treated are individuals born in months 1 to 5 and control individuals are those born in months 8 to 12. Cohorts included; 1954-1975. Robust standard errors clustered by cohort.

Source: Survey on health and sexual habits (2003). 
Table 16. Probability of reporting to be being happy, satisfied and in good health.

\begin{tabular}{lcccccc}
\hline & \multicolumn{2}{c}{ Happy } & \multicolumn{2}{c}{ Satisfied } & \multicolumn{2}{c}{ Good Health } \\
\hline & MEN & WOMEN & MEN & WOMEN & MEN & WOMEN \\
Treat & & & & & & \\
& -0.060 & 0.030 & 0.017 & 0.110 & 0.012 & -0.017 \\
Treatpost & $(0.095)$ & $(0.038)$ & $(0.097)$ & $(0.116)$ & $(0.086)$ & $(0.071)$ \\
& 0.088 & $-0.092^{*}$ & -0.056 & -0.143 & 0.082 & -0.006 \\
Post & $(0.109)$ & $(0.050)$ & $(0.123)$ & $(0.127)$ & $(0.099)$ & $(0.075)$ \\
& 0.103 & $0.057^{* *}$ & 0.043 & 0.053 & $0.428^{* * *}$ & $0.264^{* * *}$ \\
Constant & $(0.077)$ & $(0.027)$ & $(0.090)$ & $(0.051)$ & $(0.070)$ & $(0.026)$ \\
& $0.707^{* * *}$ & $0.992^{* * *}$ & $0.988^{* * *}$ & $0.972 * * *$ & $0.491^{* * *}$ & $0.754^{* * *}$ \\
& $(0.063)$ & $(0.009)$ & $(0.065)$ & $(0.029)$ & $(0.057)$ & $(0.017)$ \\
Observations & 211 & 194 & 210 & 194 & 212 & 194 \\
R-squared & 0.123 & 0.101 & 0.125 & 0.206 & 0.115 & 0.089 \\
\hline
\end{tabular}

Robust standard errors in parentheses

*** $\mathrm{p}<0.01, * * \mathrm{p}<0.05, * \mathrm{p}<0.1$

Note: The dependent variable is the probability of reporting to be happy, satisfied and in good health. Regressions include cohort dummies. Treated are individuals born in months 1 to 6 and control individuals are those born in months 7 to 12 . Cohorts included; 1955-1977. Robust standard errors clustered by cohort.

Source: World Value Survey $\left(2007 ; 5^{\text {th }}\right.$ wave). 


\section{APPENDIX}

Figure A1. Incentives of individuals born at the beginning and end of the year before the reform.

Figure A2. Incentives of individuals born at the beginning and end of the year after the reform. 
Figure A3. Summary of labor market and education reforms and differential incentives of individuals born at the beginning and end of the year.

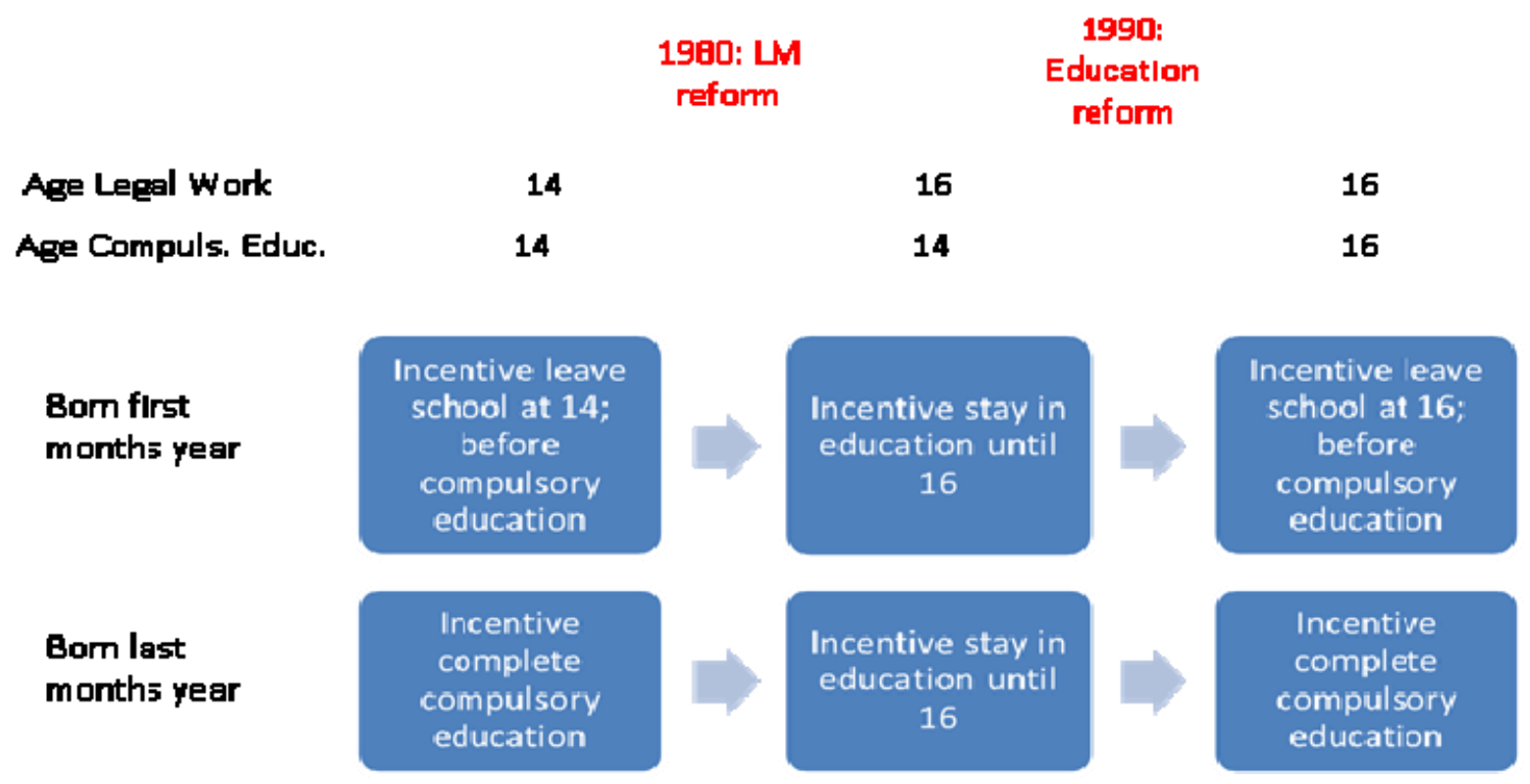

Figure A4. Probability of being an ESL; 2001 census data.

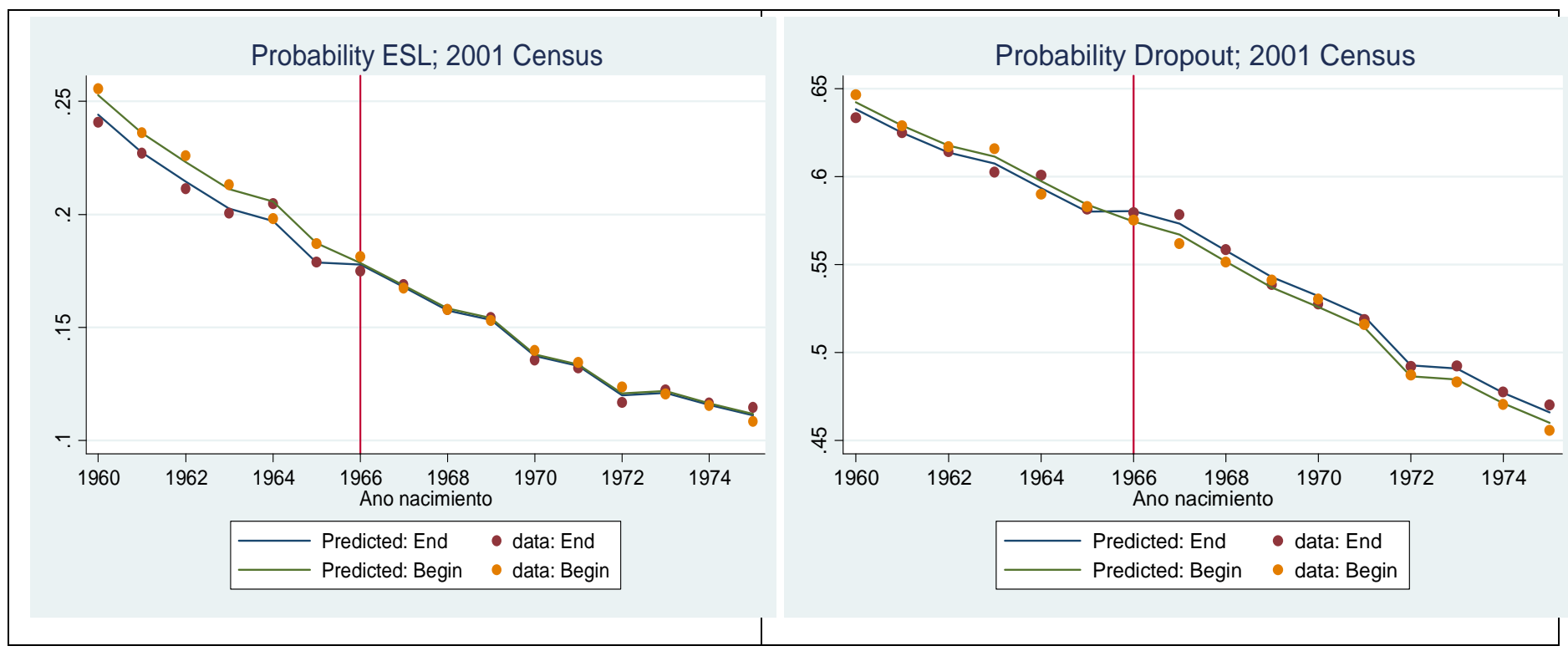

Note: The predictions are from a regression of the probability of being a dropout with cohort dummies and the dummies to identify the effect of the policy. Begin are individuals born in months 1 to 5 and end are those born in months 8 to 12 .

Source: Census 2001 (5\% sample of all population excluding immigrants). 
Table A1. ESL and dropout (2001 Census data). Full Sample.

\begin{tabular}{|c|c|c|c|c|}
\hline & \multicolumn{2}{|c|}{ Full Sample } & \multicolumn{2}{|c|}{ Reduced Sample } \\
\hline & ESL & DROPOUT & ESL & DROPOUT \\
\hline \multirow[t]{2}{*}{ treat } & $0.858 * *$ & 0.392 & $0.822 * *$ & $0.902 * *$ \\
\hline & $(0.320)$ & $(0.350)$ & $(0.340)$ & $(0.391)$ \\
\hline \multirow[t]{2}{*}{ treatpost } & $-0.844 * *$ & $-1.024 * *$ & $-0.963 * *$ & $-1.804 * * *$ \\
\hline & $(0.344)$ & (0.410) & $(0.374)$ & $(0.495)$ \\
\hline \multirow[t]{2}{*}{ postref } & $-8.979 * * *$ & $-9.285 * * *$ & $-6.951 * * *$ & $-5.895 * * *$ \\
\hline & $(0.174)$ & $(0.207)$ & (0.191) & $(0.252)$ \\
\hline \multirow[t]{2}{*}{ Constant } & $22.743 * * *$ & $62.507 * * *$ & $22.622 * * *$ & $61.606 * * *$ \\
\hline & $(0.162)$ & $(0.177)$ & $(0.174)$ & $(0.200)$ \\
\hline Observations & 389,755 & 389,755 & 239,154 & 239,154 \\
\hline R-squared & 0.014 & 0.013 & 0.014 & 0.013 \\
\hline
\end{tabular}

Robust standard errors in parentheses

$* * * \mathrm{p}<0.01, * * \mathrm{p}<0.05, * \mathrm{p}<0.1$

Note: The dependent variable is the probability of being and ESL or a dropout multiplied by 100. Regressions include cohort fixed effects. Treat are individuals born in months 1 to 5 and the control group are those born in months 8 to 12. Includes cohorts from 1960 to 1975 (cohort of 1966 excluded).

Source: Census 2001 (5\% sample).

Figure A5. Sample selection for mortality register data

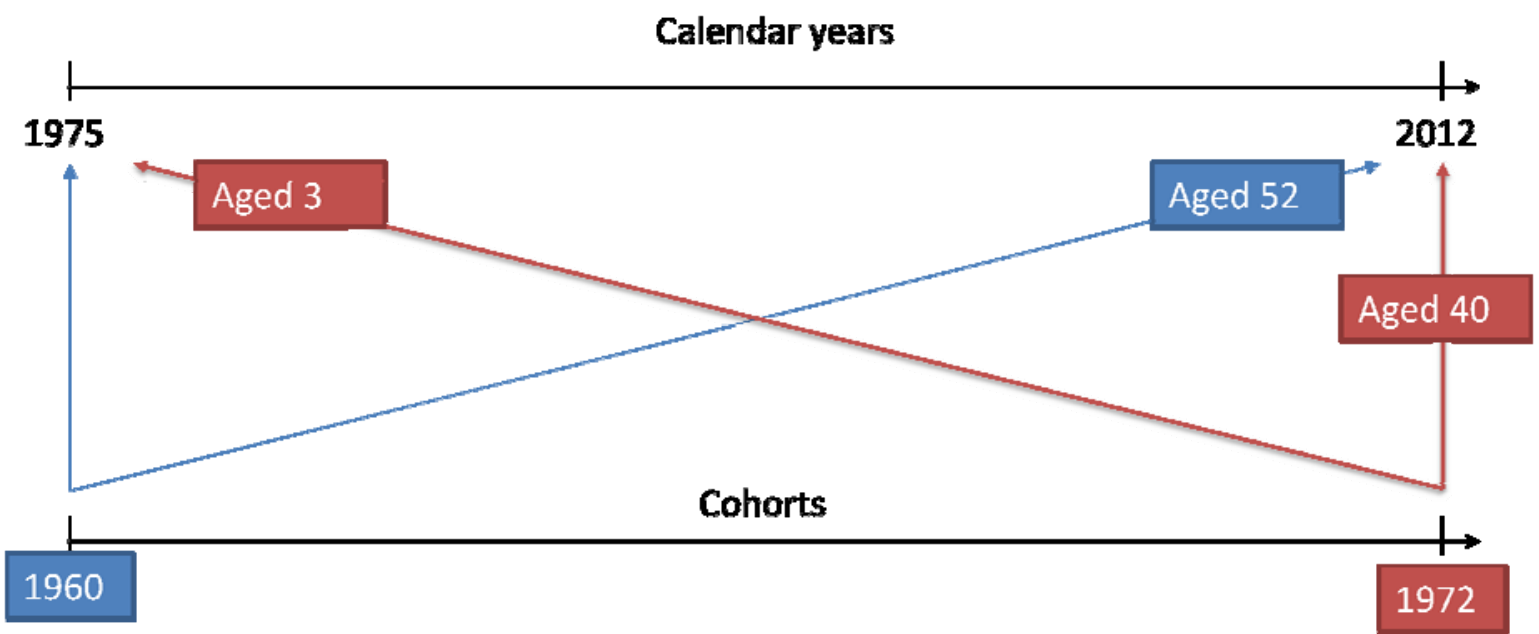


Figure A6. Probability of dying for individuals in each cohort, 2007-2013.

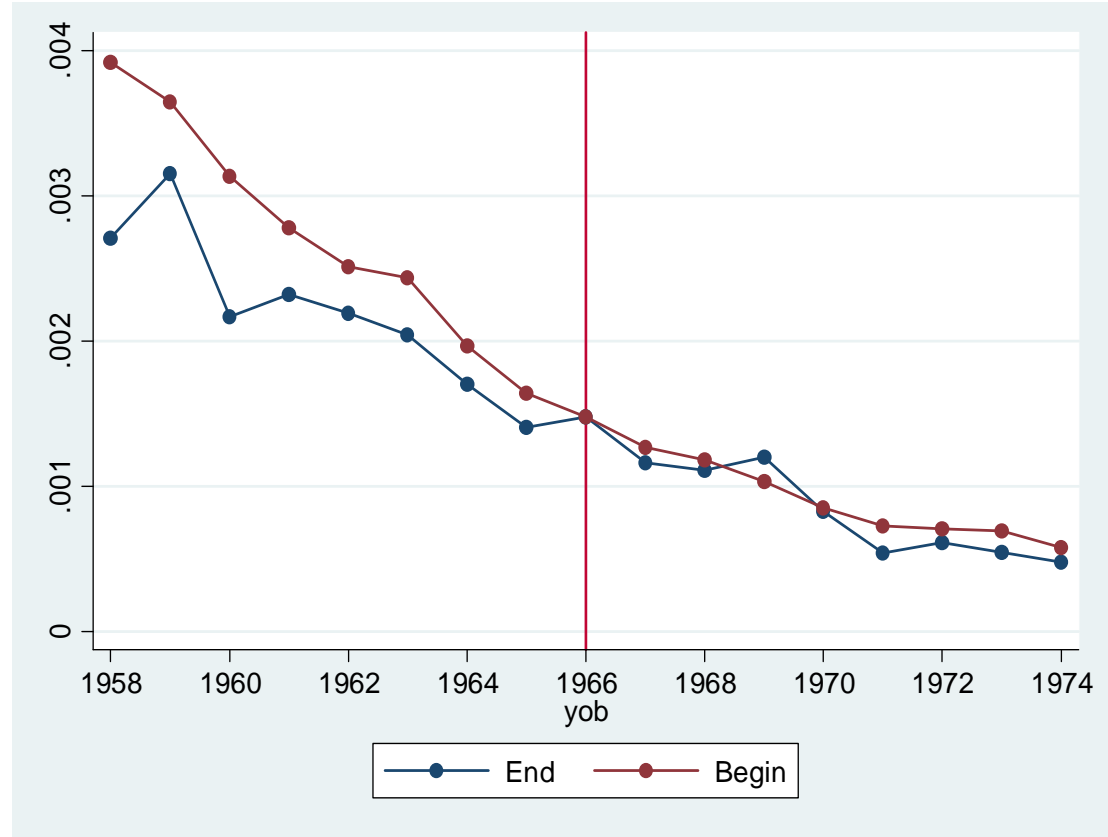

Note: Probability of dying between 2007 and 2013 for individuals in each cohort. Begin are individuals born in months 1 to 5 and end are those born in months 8 to 12 .

Source: Administrative Social Security Records (MCVL) (2007-2013).

Table A2. Probability of dying 2007-2013 (MCVL). Full Sample.

\begin{tabular}{|c|c|c|c|c|c|c|}
\hline & & Men & & & Women & \\
\hline \multirow[t]{2}{*}{ treat } & $0.0014 * * *$ & 0.0002 & 0.0002 & 0.0002 & -0.00003 & -0.00003 \\
\hline & (0.0003) & $(0.0001)$ & $(0.0001)$ & $(0.0002)$ & (0.00008) & (0.00009) \\
\hline \multirow[t]{2}{*}{ treatpost } & $-0.0014 * * *$ & $-0.0003^{*}$ & $-0.0003^{*}$ & -0.0001 & 0.00007 & 0.00007 \\
\hline & (0.0004) & $(0.0001)$ & $(0.0001)$ & $(0.0003)$ & $(0.00011)$ & (0.00011) \\
\hline \multirow[t]{2}{*}{ post } & $-0.0014^{* *}$ & 0.0001 & 0.0001 & $-0.0010^{* *}$ & -0.00012 & -0.00012 \\
\hline & $(0.0006)$ & $(0.0002)$ & $(0.0002)$ & $(0.0004)$ & $(0.00017)$ & (0.00017) \\
\hline \multirow[t]{2}{*}{ ed1 } & & $0.0003^{* * *}$ & $0.0003 * * *$ & & -0.00006 & -0.00006 \\
\hline & & $(0.0001)$ & $(0.0001)$ & & (0.00007) & (0.00007) \\
\hline \multirow[t]{2}{*}{ ed2 } & & $0.0001^{*}$ & 0.0001 & & 0.00005 & 0.00005 \\
\hline & & $(0.0001)$ & $(0.0001)$ & & (0.00007) & (0.00007) \\
\hline \multirow[t]{2}{*}{ Constant } & $-0.0041^{* * *}$ & $-0.0009 * * *$ & $-0.0010 * * *$ & $-0.0017 * * *$ & -0.00019 & -0.00015 \\
\hline & (0.0004) & (0.0002) & $(0.0002)$ & (0.0003) & (0.00015) & $(0.00016)$ \\
\hline Province FE & & & $x$ & & & $x$ \\
\hline Cohort FE & $x$ & $x$ & $x$ & $x$ & $x$ & $x$ \\
\hline Observations & $1,239,502$ & $1,170,697$ & $1,170,697$ & 997,140 & 953,340 & 953,340 \\
\hline Number of id & 211,617 & 201,208 & 201,208 & 179,370 & 172,878 & 172,878 \\
\hline
\end{tabular}

Standard errors in parentheses

$* * * p<0.01, * * p<0.05, * p<0.1$

Note: The dependent variable is the probability of dying in the Social Security database (MCVL). Random Effects model. Regressions include cohort dummies and a linear year trend. Treated are individuals born in months 1 to 5 and control are those born in months 8 to 12 . Cohorts included from 1958 to 1974.

Source: Social Security administrative database (2007-2013). 